\title{
Short-Term Plasticity during Intrathalamic Augmenting Responses in Decorticated Cats
}

\author{
Mircea Steriade and Igor Timofeev \\ Laboratoire de Neurophysiologie, Faculté de Médecine, Université Laval, Quebec, Canada G1K 7P4
}

The intrathalamic mechanisms of frequency-dependent augmenting responses were investigated in decorticated cats by means of intracellular recordings from thalamocortical (TC) neurons in ventrolateral (VL) nucleus, including simultaneous impalements from two TC neurons. Pulse trains $(10 \mathrm{~Hz})$ applied to VL nucleus elicited two types of augmenting responses: (1) in $68 \%$ of cells, the incremental responses occurred on a progressive depolarization associated with the decrease in IPSPs produced by preceding stimuli in the train; (2) in the remaining cells, progressively growing low-threshold ( $L T)$ responses resulted from the enhancement of $\mathrm{Cl}^{-}$-dependent IPSPs, giving rise to postinhibitory rebound bursts, followed by a selfsustained sequence of spindle waves. Although in some TC cells the augmenting responses developed from LT responses once the latter reached a given level of depolarization, other neurons displayed augmenting responses immediately after the early antidromic spike that depolarized the neuron to the required level, without an intermediate step of LT rebound. Re- peated pulse trains led to a progressive and persistent increase in slow depolarizing responses of TC cells, as well as to a persistent and prolonged decrease in the amplitudes of the IPSPs. On the basis of parallel experiments, we propose that the two types of augmentation in TC cells are a result of contrasting responses of thalamic reticular neurons evoked by repetitive thalamic stimuli: decremental responses, which may account for disinhibition leading to depolarizing responses in TC cells, and incremental responses, explaining the progressive hyperpolarization of TC cells. These data demonstrate that frequency-dependent changes in neuronal excitability are present in the thalamus of a decorticated hemisphere and suggest that short-term plasticity processes in the gateway to the cerebral cortex may decisively influence cortical excitability during repetitive responses.

Key words: augmenting; plasticity; thalamus; intracellular; high-threshold; low-threshold
Rhythmic (around $10 \mathrm{~Hz}$ ) stimulation of dorsal thalamic nuclei elicits responses in related neocortical areas that grow in size during the first stimuli (Morison and Dempsey, 1943). The augmenting (or incremental) responses have also been obtained by stimulating the white matter (Morin and Steriade, 1981; Ferster and Lindström, 1985) or callosal pathways (Nuñez et al., 1993; Steriade et al., 1993b) in thalamic-lesioned animals. Although the patterns of incremental cortical responses to white matter stimulation differed from those of thalamic-evoked potentials (Morin and Steriade, 1981), it was generally assumed that the intrinsic organization of the cerebral cortex subserves the frequencydependent augmentation. Recently, the spatiotemporal features of augmenting responses have been investigated in rat motor cortex, and it was proposed that the initiation of these responses, related to short-term plasticity processes, depends on the intrinsic properties and synaptic interconnections of layer $\mathrm{V}$ pyramidal cells (Castro-Alamancos and Connors, 1996a-c).

Although there is as yet no study of cellular mechanisms underlying intrathalamic augmenting responses, previous experimental data would favor the possibility that augmenting potentials are generated within the thalamus in the absence of cortex. Spindles, an oscillation that marks the sleep onset in mammals, display a pattern of initially growing field potentials very similar to

Received Nov. 5, 1996; revised Jan. 28, 1997; accepted Feb. 21, 1997.

This study was supported by the Medical Research Council of Canada and Human Frontier Science Program. I.T. is a postdoctoral fellow, partially supported by the Savoy Foundation. We thank D. Giguère and D. Drolet for technical assistance. Correspondence should be addressed to Prof. Steriade at the above address.

Copyright (C) 1997 Society for Neuroscience $0270-6474 / 97 / 173778-\bullet \$ 05.00 / 0$ those of augmenting responses. In fact, the latter have been investigated in an attempt to mimic spontaneously occurring spindles (Morison and Dempsey, 1942). Sleep spindles are generated in the thalamus after decortication (Morison and Bassett, 1945) through interactions between thalamic reticular (RE) and thalamocortical (TC) cells (Steriade and Deschênes, 1984; Steriade et al., 1990). The initial waxing of spindles is a result of the recruitment of thalamic cells (Andersen and Andersson, 1968) resulting from RE-induced IPSPs in TC cells, followed by postinhibitory rebound spike bursts transmitted back to RE neurons as well as to cortical neurons (Steriade and Llinás, 1988; Steriade et al., 1993a; Bal et al., 1995a,b). The divergent projections of RE neurons to the dorsal thalamus (Jones, 1985) succeed in recruiting TC cells. Besides, corticothalamic neurons potentiate the genesis and synchronization of spindles (Steriade et al., 1972; Contreras and Steriade, 1996). However, the presence of spindles in the thalamus of decorticated animals (Morison and Bassett, 1945; Contreras et al., 1996; Timofeev and Steriade, 1996) and even in thalamic slices with preserved RE-TC circuitry (von Krosigk et al., 1993; Bal et al., 1995a,b) suggests that the thalamic machinery is necessary and sufficient for the development of oscillatory responses with incremental features.

Here we demonstrate augmenting responses of thalamic neurons in decorticated cats, and we investigate their mechanisms by means of intracellular recordings, including simultaneous impalements of two TC cells. The results show two types of augmentation in TC cells, resulting from their progressive depolarization or hyperpolarization. We relate these contrasting aspects to the decremental or incremental responses in GABAergic RE neurons 
(Steriade and Timofeev, 1996) and to a subtle balance between excitatory and inhibitory inputs acting on TC cells. Our results indicate that the two different types of incremental responses in thalamic neurons depend on their intrinsic properties, network operations, and place in the circuitry formed by TC-RE synaptic interactions. We suggest that augmenting responses play a role in short-term thalamic plasticity processes.

\section{MATERIALS AND METHODS}

Experiments were conducted on adult cats of either sex $(n=43)$, most of them $(n=40)$ anesthetized with ketamine and xylazine $(10-15 \mathrm{mg} / \mathrm{kg}$ and 2-3 mg, i.m.); the remaining three animals were anesthetized with urethane $(1.8 \mathrm{gm} / \mathrm{kg}$, i.p.). The tissues to be excised and the pressure points (because of contention of animals in a stereotaxic apparatus) were infiltrated with lidocaine $(2 \%)$. The animals were paralyzed with gallamine triethiodide and artificially ventilated by maintaining the end-tidal $\mathrm{CO}_{2}$ concentration at $3.5-3.8 \%$. The left cerebral cortex was ablated by suction (Fig. 1). The depth of the anesthesia was ascertained by continuously recording the cortical electroencephalogram (EEG) from the right hemisphere and the left electrothalamogram (EThG) through coaxial electrodes, and additional doses of anesthetics were administered at the slightest tendency toward increasing the frequency and/or diminishing the amplitudes of EEG and EThG waves. Rectal temperature $\left(37-39^{\circ} \mathrm{C}\right)$ and heart beat were also monitored. The stability of intracellular recordings was ensured by bilateral pneumothorax, cisternal drainage, hip suspension, and by covering the left (decorticated) hemisphere with a warm agar solution (4\% in $1 \%$ saline).

Stimulation and intracellular recordings. A coaxial stimulating electrode was inserted after hemidecortication in the left thalamus, within the ventrolateral (VL) nucleus. Stimuli were delivered with variable durations $(0.05-0.2 \mathrm{msec})$ and intensities $(0.02-0.3 \mathrm{~mA})$. Intracellular recordings of VL thalamic neurons were performed in the decorticated hemisphere with glass micropipettes (tip, $\sim 0.5 \mu \mathrm{m}$; resistance, 35-80 M $\Omega$ ) filled with K-acetate $(3 \mathrm{M})$, K-acetate $(1 \mathrm{M})$ plus $\mathrm{KCl}(2 \mathrm{M})$, or K-acetate $(2.5 \mathrm{M})$ plus $\mathrm{KCl}(0.5 \mathrm{M})$. The recorded cells were located $2-3 \mathrm{~mm}$ from the stimulating electrode. A high-impedance amplifier with active bridge circuitry was used to record the membrane potential $\left(\mathrm{V}_{\mathrm{m}}\right)$ and inject current into the cells. Intracellular activities were recorded, together with field potentials, on an eight-channel tape with a bandpass of $0-9 \mathrm{kHz}$, digitized at $20 \mathrm{kHz}$ for off-line computer analysis.

Histology. At the end of experiments, the animals were given a lethal dose of pentobarbitone and perfused intracardially with physiological saline, followed by $10 \%$ formaldehyde. The extent of hemidecortication and the callosal cut was verified on coronal sections $(80 \mu \mathrm{m})$ stained with thionine.

\section{RESULTS}

The results are presented as follows. First, we show data demonstrating the progressive reduction in IPSPs of VL cells at stimuli rates of $\geq 1 \mathrm{~Hz}$, the progressive increase in their depolarizing responses at rates of $10 \mathrm{~Hz}$, and the frequency dependency of these augmenting responses that develop at a $\mathrm{V}_{\mathrm{m}}$ more positive than $-55 \mathrm{mV}$. Next, we present the other type of incremental responses, built up by progressive hyperpolarizations in TC cells (beyond $-70 \mathrm{mV}$ ), leading to increasing low-threshold (LT) postinhibitory spike bursts. Finally, we demonstrate the two types of intrathalamic augmenting responses by means of simultaneous intracellular recordings from two VL neurons.

\section{Extent of hemidecortication, database, and identification of TC neurons}

The histological control of the decorticated hemisphere showed a total ablation of areas that have connections with VL, as well as with the adjacent dorsal thalamic nuclei and the related rostrolateral sectors of the RE nucleus. In fact, the hemidecortication extended to virtually all sensory, motor, and association neocortical fields (Fig. 1). The only region of the cerebral cortex that was left intact on its ventral side belonged to perirhinal and entorhinal cortices. In some experiments, we succeeded in removing even those regions around the rhinal sulcus, thus leaving intact only the prepiriform and periamygdaloid cortices, which do not have connections with VL or other ventral nuclei. The lateral bank of the rhinal sulcus projects to some thalamic nuclei (reuniens, suprageniculate, and medial geniculate) far away from the region explored here, and the enthorhinal cortex receives afferents from some midline nuclei, but this thalamic connection is not reciprocated (Room and Groenewegen, 1986; Witter et al., 1989).

The results are based on intracellular recordings of 187 neurons from the VL nucleus of the decorticated hemisphere. Neurons were recorded for $20 \mathrm{~min}$ to $2 \mathrm{hr}$. Their resting $\mathrm{V}_{\mathrm{m}}$ was usually more negative than $-60 \mathrm{mV}$ (mean, $-64 \pm 2.2 \mathrm{mV}$ ). Only 15 cells had a resting $\mathrm{V}_{\mathrm{m}}$ more positive than $-60 \mathrm{mV}$, and in 29 cells the resting $\mathrm{V}_{\mathrm{m}}$ was more negative than $-70 \mathrm{mV}$. The action potentials were overshooting. The apparent input resistance $\left(\mathrm{R}_{\mathrm{in}}\right.$, measured by applying short hyperpolarizing pulses) was $23.4 \pm 1.1 \mathrm{M} \Omega$. The typical response of a VL cell to single-shock stimulation within the VL nucleus (Fig. 2) consisted of: (1) an early depolarization, with an antidromic spike (the latency varied from 0.3 to $0.5 \mathrm{msec}$; see also Figs. 4, 6), followed by an orthodromic excitation with one or two action potentials at a latency of 1.5 to $6 \mathrm{msec}$ (see also Fig. 4); (2) a long-lasting hyperpolarization with two components, similar to $\mathrm{GABA}_{\mathrm{A}}$ - and $\mathrm{GABA}_{\mathrm{B}}$-mediated IPSPs described in vitro (Hirsch and Burnod, 1987; Crunelli et al., 1988) and in vivo (Paré et al., 1991); and (3) a postinhibitory LT spike, often crowned by a burst of fast $\mathrm{Na}^{+}$action potentials (Fig. 2). Of $187 \mathrm{VL}$ cells, 151 $(81 \%)$ displayed augmenting responses.

All recorded VL cells belonged to the TC class. The following features distinguished them from local circuit inhibitory interneurons. First, the duration of action potentials (width at half amplitude in antidromically elicited spikes) measured $0.8-0.9 \mathrm{msec}$ (see Figs. 2, 4, 6), whereas spikes generated by interneurons are on average much shorter, about $0.35 \mathrm{msec}$ (Pape and McCormick, 1995). Second, the rebound, high-frequency $(>250 \mathrm{~Hz})$ spike bursts characterized all recorded TC cells (see Figs. 2, 4, 8), whereas local interneurons do not exhibit such bursts (McCormick and Pape, 1988), or when they do, bursts are sluggish, with a maximum intraburst frequency of $130 \mathrm{~Hz}$ (Williams et al., 1996). In vitro studies (Pape and McCormick, 1995) revealed that the absence of robust rebound spike bursts in local thalamic interneurons is a result of the masking of the $\mathrm{Ca}^{2+}$-mediated LT response, found in virtually all TC cells (Jahnsen and Llinás, 1984), by the transient $\mathrm{K}^{+}$current, $\mathrm{I}_{\mathrm{A}}$. Third, the TC examined in the present study oscillated intrinsically within the $\Delta$ frequency $(1-4 \mathrm{~Hz})$, either spontaneously, at a $\mathrm{V}_{\mathrm{m}}$ level more negative than $-72 \mathrm{mV}$, or evoked by thalamic stimuli, as demonstrated previously in antidromically identified TC neurons (see Fig. 7 in Steriade et al., 1991a). This clock-like oscillation, resulting from an interplay between $\mathrm{I}_{\mathrm{H}}$ and $\mathrm{I}_{\mathrm{T}}$ (McCormick and Pape, 1990; Soltesz et al., 1991), is characteristic for TC cells. Fourth, antidromic responses, similar to those obtained by stimulating the thalamus (see Figs. 2, 4), have been elicited from the internal capsule (not shown).

\section{Reduction in IPSP-rebound sequences and augmenting responses from depolarized levels}

Of $151 \mathrm{VL}$ neurons that displayed augmenting responses to rhythmic thalamic stimuli at $10 \mathrm{~Hz}, 94$ neurons $(62 \%)$ developed such responses at relatively depolarized levels (more positive than $-55 \mathrm{mV}$ ).

With thalamic stimuli at rates equal or higher than $1 \mathrm{~Hz}$, the amplitudes of IPSPs evoked in VL cells diminished by about 25-40\%, and, correlatively, the full-blown postinhibitory spike 

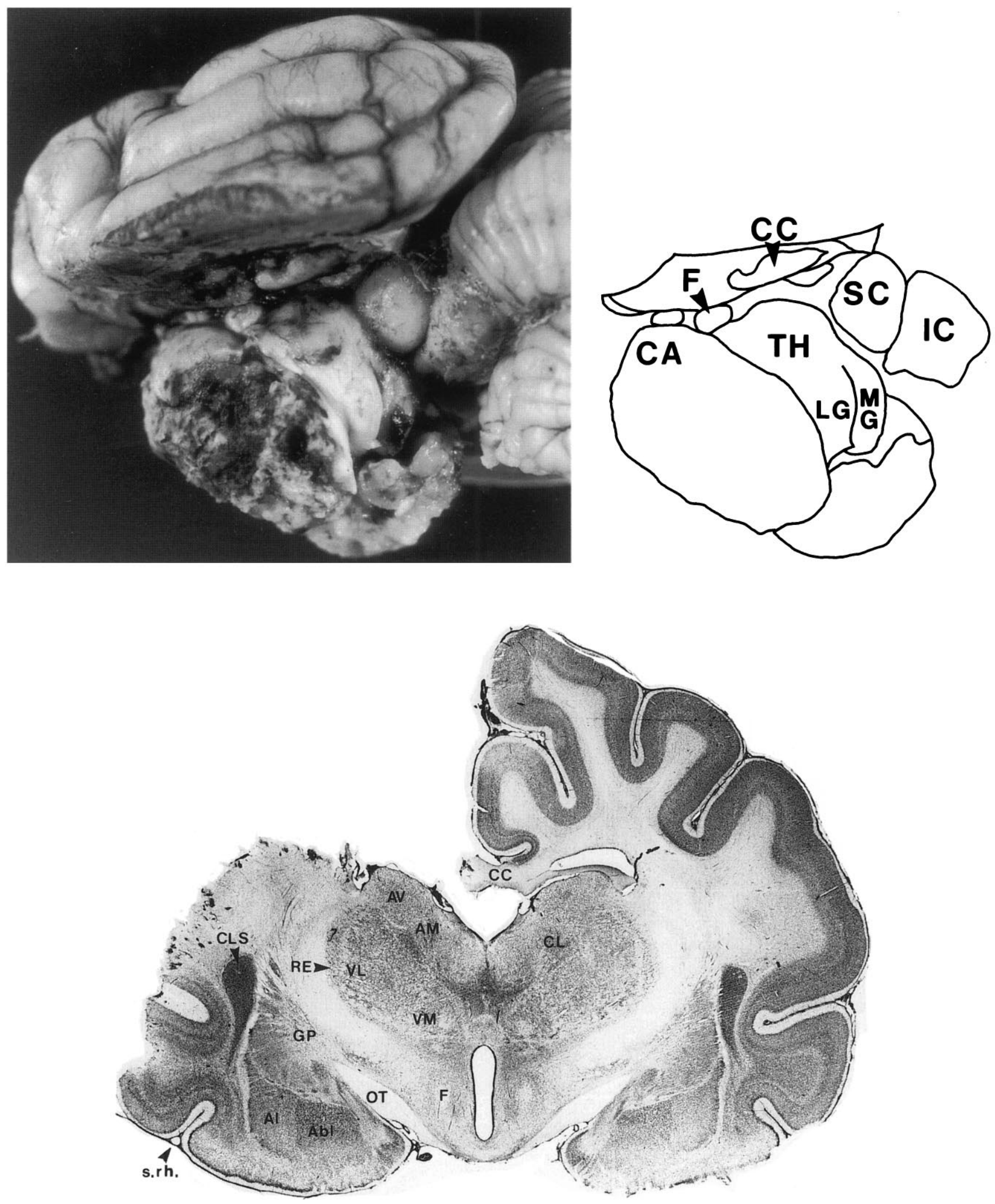

Figure 1. The thalamus after ipsilateral removal of neocortex and cut of corpus callosum. Top, Dorsal view of the brain showing the extent of hemidecortication. Right, Scheme with subcortical structures in the left (decorticated) hemisphere. $C A$, Caudate nucleus; $C C$, corpus callosum; $F$, fornix; $I C$, inferior colliculus; $S C$, superior colliculus; $T H$, thalamus; $L G$ and $M G$, lateral and medial geniculate nuclei. Bottom, Nissl-stained frontal section showing the extent of hemidecortication. Note the cut of CC. $A V, A M, C L, R E, V L$, and $V M$, Anteroventral, anteromedial, central lateral, reticular, ventrolateral, and ventromedial thalamic nuclei, respectively; $A l$ and $A b l$, lateral and basolateral nuclei of amygdala; $C L S$, claustrum; $G P$, globus pallidus; OT, optic tract; s.rh., rhinal sulcus (arrowhead). 


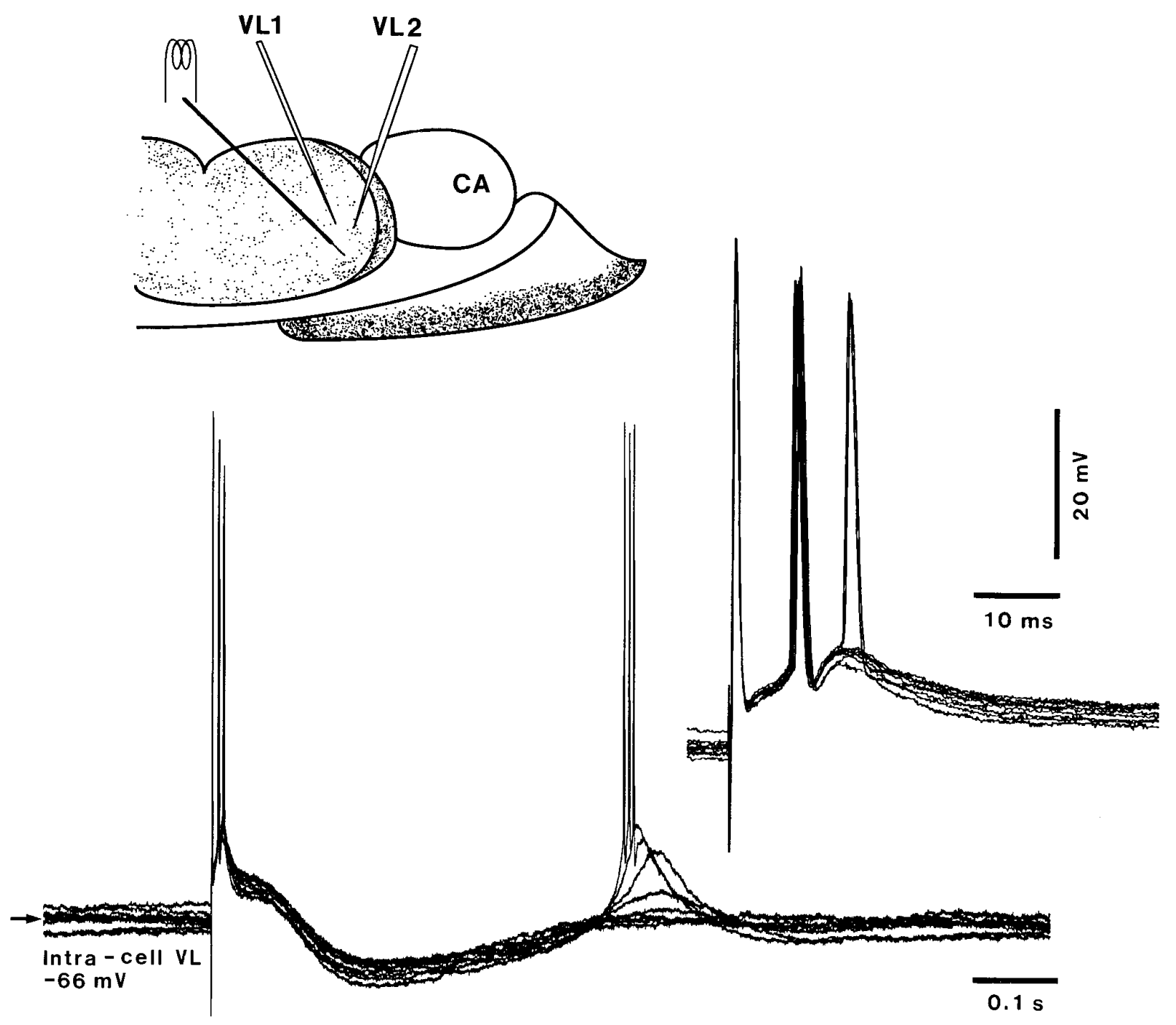

Figure 2. Responses of TC cells to local thalamic stimulation. The diagram shows the location of two micropipettes in the VL nucleus $(1,2)$ and one stimulating electode within the VL nucleus. Below, thalamic-evoked response of TC cell from the VL nucleus. The early part of the response is expanded in the above inset showing an antidromic spike, followed by a synaptic response consisting of one or occasionally two action potentials. In this and following figures, $\mathrm{V}_{\mathrm{m}}$ is indicated.

bursts were reduced to an LT response in isolation that eventually disappeared at successive stimuli (Fig. $3 A$ ). A similar reduction in IPSPs and rebound bursts was observed when, instead of using single thalamic stimuli, two 100 -msec-delayed stimuli were delivered at a frequency of $1 \mathrm{~Hz}$ (Fig. $3 B$ ). Close examination of responses to the paired stimuli revealed a progressive increase in the number of action potentials on a growing slow depolarization, in parallel to the diminished inhibitory-rebound sequences $(n=$ $22)$. In the example of Figure $3 B$, from one and three orthodromic spikes evoked by the first and second stimuli in the initial pair (the first action potential was antidromic), the synaptic responses reached three and four spikes to the first and second stimuli in the last pair of testing stimuli. This was associated with an increase in spike threshold, a consistent finding in all 22 neurons tested.

We used different stimulation protocols to observe, during a sequence of pulse trains at different frequencies, the temporal evolution of IPSPs and the degree of augmentation. At low rates $(0.5 \mathrm{~Hz})$ of single stimuli, the successive IPSP and rebound bursts remained unchanged or only slightly diminished (see first two response sequences in Fig. 4). Repetitive stimuli $(10 \mathrm{~Hz})$ grouped in sequences recurring at $0.5 \mathrm{~Hz}$ led to augmenting responses as well as to the absence of IPSPs and rebound bursts, whereas returning to the single-shock stimulation fully restored the IPSPs and the postinhibitory rebound bursts (Fig. 4). Figure 4, panel 2, depicting the expanded responses to five stimuli at $10 \mathrm{~Hz}$ seen in the top record, demonstrates that, by increasing the number of testing stimuli (compared with two stimuli, used in the previous Fig. 3), the augmenting responses became even more dramatic. In this VL neuron (that responded with an antidromic spike followed by one or two orthodromic spikes to single-shock stimulation; see Figure 4, panel 1), repetitive VL stimuli at $10 \mathrm{~Hz}$ induced a progressive increase in the number of action potentials in response to successive stimuli in the pulse train, leading to spike inactivation ( panel 2).

The frequency dependency of thalamic augmentation was investigated by comparing the amount of increment at stimulation rates of $3-10 \mathrm{~Hz}(n=27)$. At $1-3 \mathrm{~Hz}$, excitatory responses did not significantly change with successive stimuli. In Figure 5, the only change 

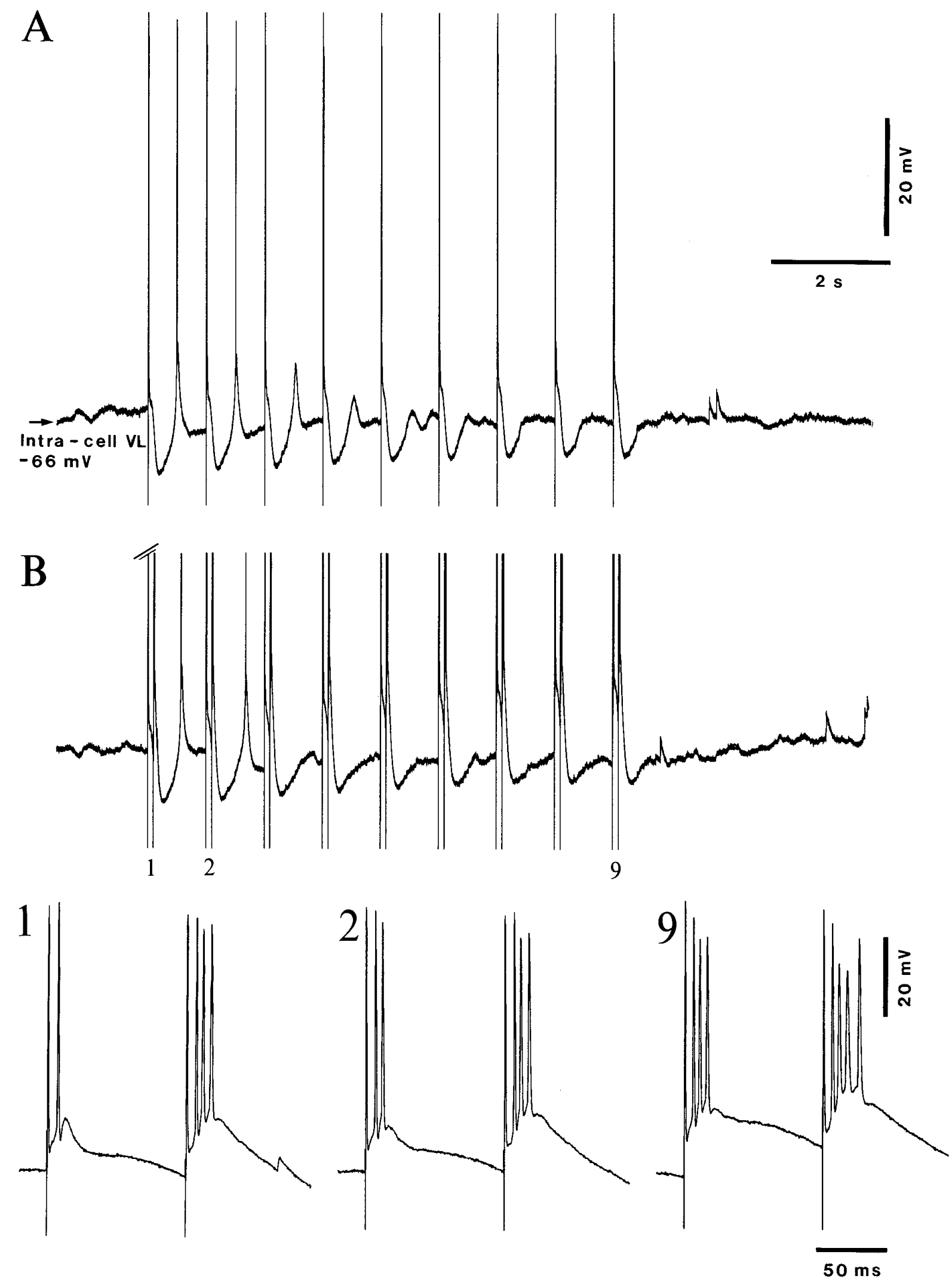

Figure 3. Progressive reduction in inhibition-rebound sequences of VL cell after repetitive thalamic stimulation at $1 \mathrm{~Hz}$. $A$, Single VL stimuli at $1 \mathrm{~Hz}$. The amplitudes of IPSP diminished from $8.5 \mathrm{mV}$ (first two stimuli) to $7.5 \mathrm{mV}$ (third stimulus) and, thereafter, down to $6 \mathrm{mV}$ (last stimulus). Such slight changes led to transformation of full-blown rebound spike bursts (first two stimuli) into the LT spike in isolation (third stimulus) and, thereafter, absence of postinhibitory rebound. $B$, Paired (100-msec-delayed) VL stimuli delivered at $1 \mathrm{~Hz}$. Note same phenomenon (diminished inhibition and rebound) as in $A$ and, in parallel, progressively augmented responses to first and second stimuli in the three expanded paired stimuli $(1,2,9)$. 


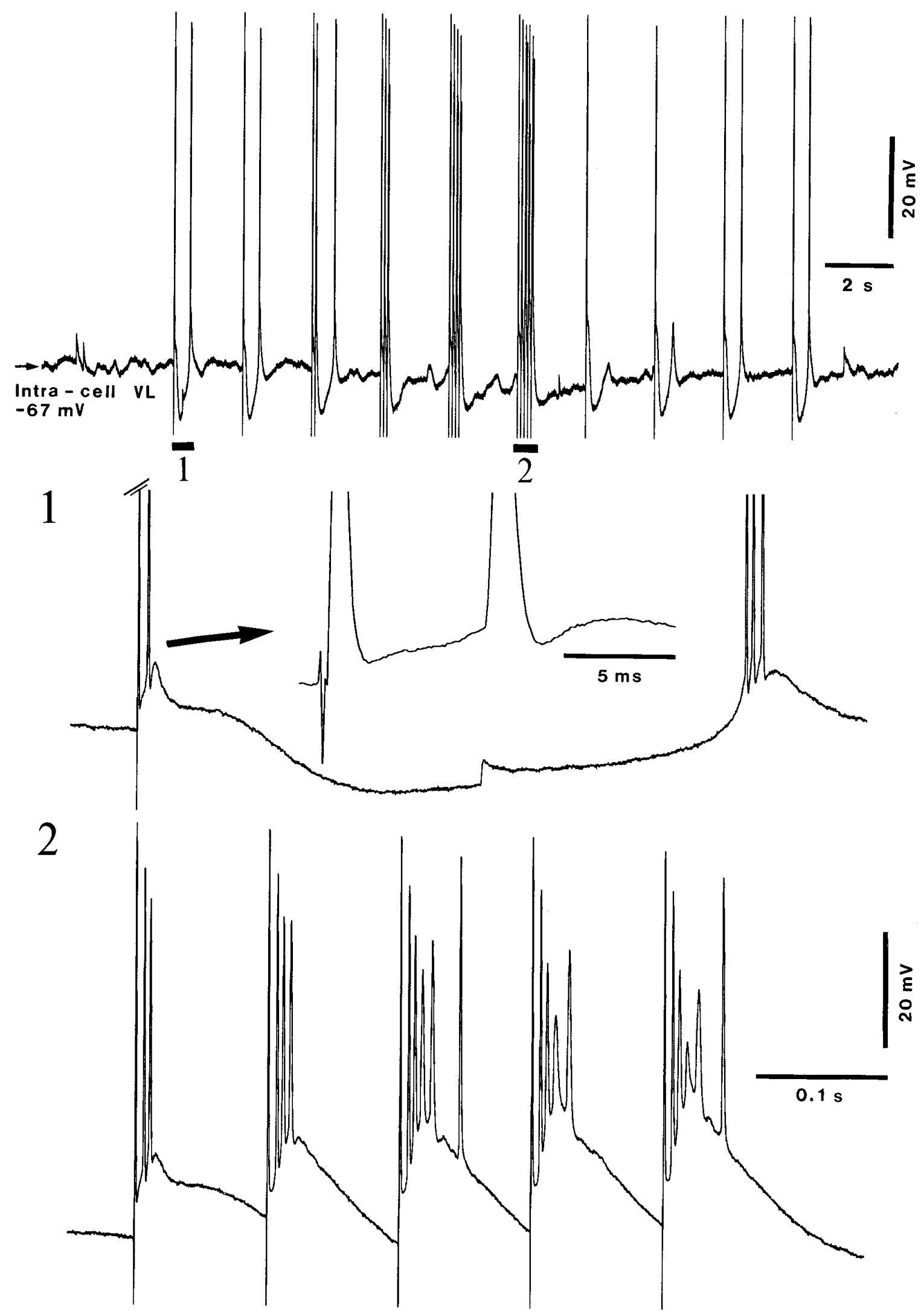

Figure 4. Decreased inhibition related to augmenting responses occurring at depolarized levels of $\mathrm{V}_{\mathrm{m}}$. Single and multiple (100-msec-delayed) pulses were delivered every $2 \mathrm{sec}$ to the VL nucleus. The response of VL cell to a single thalamic stimulus (expanded in 1) consisted of an antidromic spike (latency, $0.35 \mathrm{msec}$ ), followed by an orthodromic response (latency, $6 \mathrm{msec}$ ) and a long-lasting $(450 \mathrm{msec}$ ) hyperpolarization leading to a high-frequency spike burst. 2, Progressive augmentation of the early orthodromic response to a train of five stimuli at $10 \mathrm{~Hz}$. 


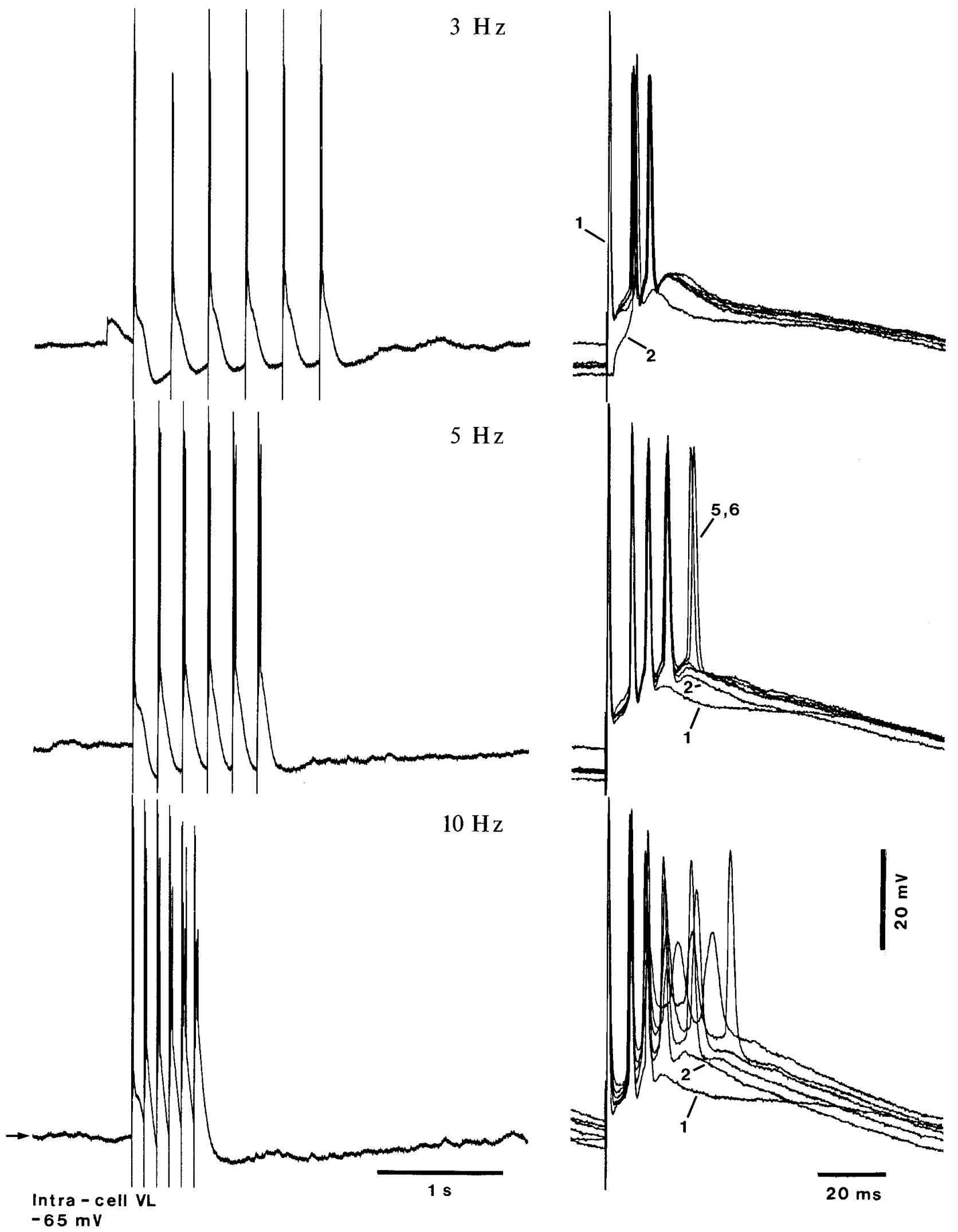

Figure 5. Frequency-dependent augmentation. The same VL cell was tested with a six-shock train to the VL nucleus at 3, 5, and $10 \mathrm{~Hz}$. Right, The responses to all stimuli in a train are superimposed and expanded. Top, 1,2, Responses to first and second stimuli in the train at $3 \mathrm{~Hz}$; note that responses to following stimuli (3-6) did not change, compared with the response to the first stimulus. Middle, 1, 2, 5, 6, Responses to the first, second, fifth, and sixth stimuli in the train at $5 \mathrm{~Hz}$. Bottom, 1,2, Responses to the first and second stimuli in the train at $10 \mathrm{~Hz}$; note progressive increase in firing threshold and spike inactivation during repetitive stimulation. 


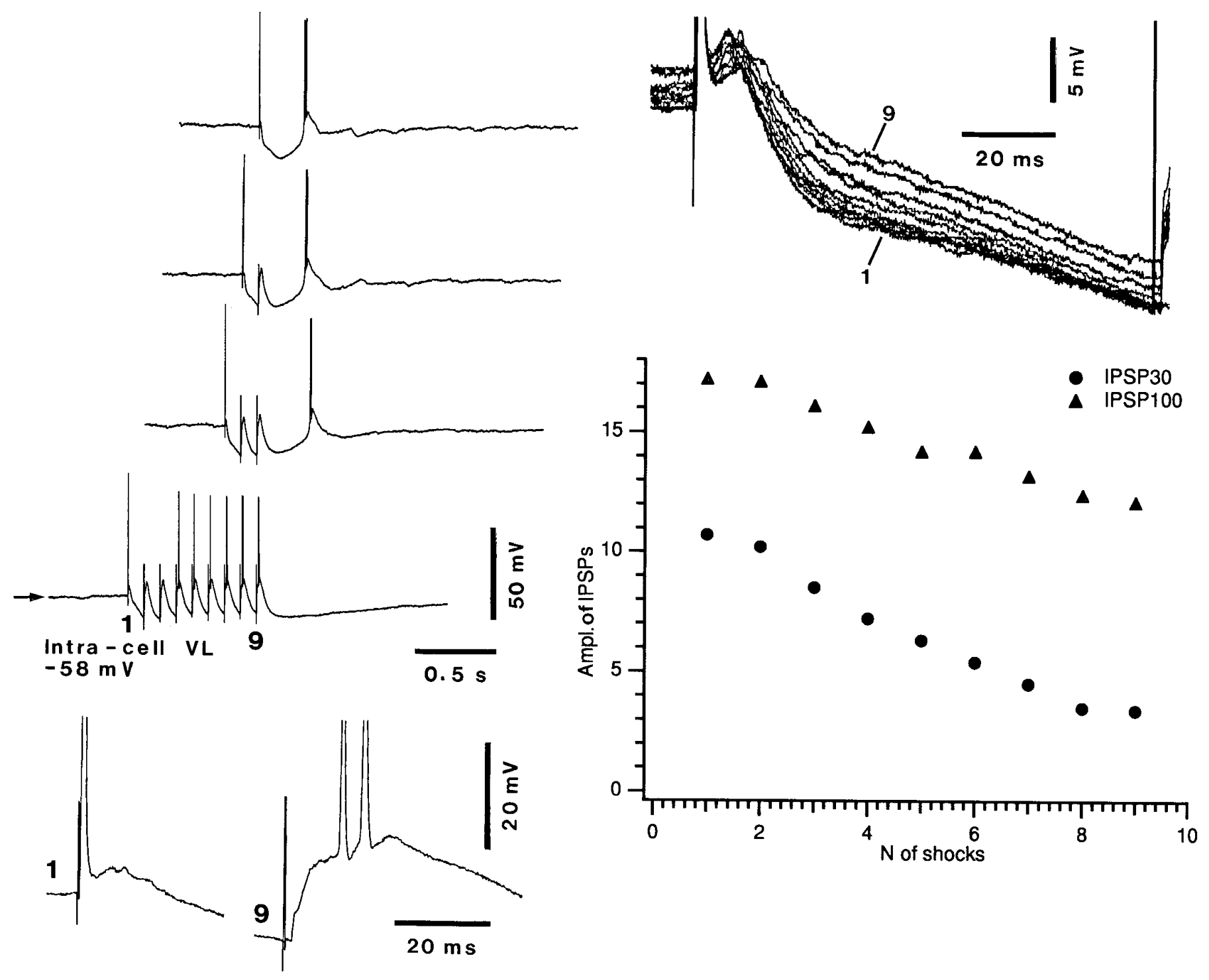

Figure 6. Diminished amplitudes of IPSPs by increasing the number of repetitive (10 Hz) VL stimuli. Left, Series of testing stimulations (from top to bottom: one, two, three, and nine shocks). Sweeps are aligned on the last stimulus in pulse trains to show increased latency and progressive reduction in the postinhibitory rebound. Below the nine-shock train, the antidromic response to the first shock and the augmented response to the ninth shock are expanded (spikes truncated). Top right, Superimposition of responses to the first stimuli in all nine pulse trains. Note progressively diminished amplitudes of IPSPs as a result of long-lasting processes elicited by the previous pulse trains. Bottom right, Amplitudes of IPSPs (ordinate) measured at 30 and 100 msec as a function of the number of testing shocks (one to nine).

observed with $3 \mathrm{~Hz}$ stimulation was the abolition of the antidromically elicited action potential at the second stimulus, falling during the hyperpolarizing phase produced by the first stimulus in the train. Thereafter, the orthodromic responses constantly had one or two action potentials. By raising the stimulation rate to $5 \mathrm{~Hz}$, the increase in the number of action potentials was obvious; from one or two spikes in response to the first stimulus, there were four action potentials at the fifth and sixth stimuli in the train. At $10 \mathrm{~Hz}$, it was a further increase in the number of action potentials, increase in firing threshold, and spike inactivation.

Repeated trains of stimuli at $10 \mathrm{~Hz}$, i.e., the optimal rate for augmenting, produced persistent and prolonged changes in inhibitory responses $(n=18)$. In Figure 6 , the TC cell was depolarized with $+0.5 \mathrm{nA}$ to enhance the amplitudes of IPSPs and pulse trains with progressively increased number of stimuli (from one to nine shocks) were delivered every $4 \mathrm{sec}$. By increasing the number of stimuli, there was an increased duration of the hyperpolarization outlasting the pulse trains and, consequently, an increased latency of the postinhibitory rebound (Fig. 6, left panel, with stimuli aligned on the last shock in the train). Comparing the IPSPs evoked by the first stimulus in successive pulse trains revealed their progressive decrease in amplitude, from pulse trains 1-9 (Fig. 6, top right panel). The plot in the bottom right panel of Figure 6 shows that the amplitude of IPSPs measured at $30 \mathrm{msec}$ from the testing VL stimulus (occurring during the $\mathrm{GABA}_{\mathrm{A}}$ component) diminished from about $10 \mathrm{mV}$ at the single-shock stimulation to about $6 \mathrm{mV}$ at the first stimulus in the fifth pulse train, to reach only $3.5 \mathrm{mV}$ at the first stimulus in the ninth pulse train. The IPSPs measured at $100 \mathrm{msec}$ (during the $\mathrm{GABA}_{\mathrm{B}}$ component) decreased from about $17 \mathrm{mV}$, initially, to $12 \mathrm{mV}$ at the first stimuli in the last pulse trains. At the same time, the spontaneous $\mathrm{V}_{\mathrm{m}}$ fluctuations did not exceed $3 \mathrm{mV}$. Together, 
these data show a persistent and prolonged diminution in amplitudes of both early and late components of IPSPs by preceding repetitive stimulation.

The decreased inhibition induced by repetitive stimulation was quantified by comparing the $\mathrm{R}_{\text {in }}$ drop associated with the IPSPs evoked by the first and fifth thalamic stimuli in a train at $10 \mathrm{~Hz}$ $(n=7)$. Control $\mathrm{R}_{\mathrm{in}}$ was estimated from the amplitude of the voltage response to a long hyperpolarizing current pulse applied at rest. The response of TC cells to such pulses reached an early peak, followed by a depolarizing sag as a result of the activation of $\mathrm{I}_{\mathrm{H}}$ (McCormick and Pape, 1990). The $\mathrm{R}_{\mathrm{in}}$ during these two phases of the response measured $24.3 \pm 1.2$ and $12.9 \pm 1.1 \mathrm{M} \Omega$, respectively. The $R_{i n}$ associated with the IPSP $(35 \mathrm{msec}$ after the stimulus) was estimated by calculating the slope resistance (the reciprocal of the slope conductance; see Johnston and Wu, 1995). The $R_{\text {in }}$ dropped to $3.16 \pm 0.3 \mathrm{M} \Omega$ during the IPSP to the first stimulus in the train but only to $7.5 \pm 1.1 \mathrm{M} \Omega$ during the IPSP to the fifth stimulus in the train.

The intrathalamic incremental responses that arose from a progressive depolarization were initiated immediately after the early excitation represented by an antidromic spike and/or EPSP $(n=50$; see Figs. 3,4$)$ or developed in two steps $(n=44$; Figs. 7 , $8)$. The first step was the transformation of the early EPSP into an LT response at a hyperpolarized $\mathrm{V}_{\mathrm{m}}$ (more negative than -65 to $-70 \mathrm{mV}$ ), as a result of the IPSP produced by the first stimulus in the train at $10 \mathrm{~Hz}$. In the second step, the LT response was truncated by a secondary depolarizing response that developed at a $\mathrm{V}_{\mathrm{m}}$ more positive than -55 to $-50 \mathrm{mV}$. These two steps are indicated by two arrows in Figures 7 and 8 .

In Figure 7, the incremental responses to a train of five stimuli at $10 \mathrm{~Hz}$ are illustrated at three levels of $\mathrm{V}_{\mathrm{m}}$ : under DC hyperpolarization, without current, and under DC depolarization. The $\mathrm{V}_{\mathrm{m}}$ was $-72 \mathrm{mV},-62 \mathrm{mV}$ at rest, and $-51 \mathrm{mV}$. Figure $7 A$ illustrates the responses to all five stimuli in the train, whereas Figure $7 B$ shows the expanded early (depolarizing) component of augmented responses (superimposed responses were offset at the initial $\mathrm{V}_{\mathrm{m}}$ ). The bottom arrow in Figure $7 B$ (middle part) indicates the inflection point where the EPSP gives rise to an LT response, whereas the top arrow (15-16 $\mathrm{mV}$ more positive) indicates the point where the LT gives rise to a secondary depolarizing response. Note that under $+0.8 \mathrm{nA}$, an early antidromic spike was revealed, and the ripples (that were subthreshold at the resting $\mathrm{V}_{\mathrm{m}}$ ) gave rise to action potentials. Overall, Figure $7 A$ demonstrates that augmenting responses develop over a progressive depolarization at the expense of hyperpolarizing periods. By illustrating the same incremental responses at the real $\mathrm{V}_{\mathrm{m}}$ (Fig. $7 C$ ), it is evident that the response to the first stimulus in the train occurred at a more depolarized $\mathrm{V}_{\mathrm{m}}$ than all other subsequent responses. As well, at the resting or more depolarized $\mathrm{V}_{\mathrm{m}}$, the augmenting response exceeded by at least $10 \mathrm{mV}$ the depolarizing response elicited by the first stimulus in the train.

In Figure 8, the pattern of augmenting responses is opposed to that of the LT spike that underlies the postinhibitory rebound burst. A single VL stimulus evoked an antidromic spike, followed by a typical biphasic $\left(\mathrm{GABA}_{\mathrm{A}-\mathrm{B}}\right)$ IPSP leading to a rebound burst, whereas a train of repetitive VL stimuli at $10 \mathrm{~Hz}$ progressively induced augmenting responses. The expanded traces (Fig. 8, bottom) illustrate the pattern of the LT-mediated high-frequency burst $(*)$, in contrast with the spike doublet that follows in the augmented responses the EPSP-LT inflection (first arrow) and the following inflection (second arrow) at about 7-8 $\mathrm{mV}$ more positive than the resting $\mathrm{V}_{\mathrm{m}}$.
The changes in augmented responses at different $\mathrm{V}_{\mathrm{m}}$ values of TC cells $(n=16)$ essentially showed that hyperpolarization produced a decreased number of action potentials at the second stimulus eliciting augmentation. Figure 9 shows that the augmented response to the second stimulus in a pulse train at $10 \mathrm{~Hz}$ decreased from four action potentials that followed the antidromic spike at the resting $\mathrm{V}_{\mathrm{m}}(-70 \mathrm{mV})$ to two action potentials under slight DC hyperpolarization $(-75 \mathrm{mV})$. This result further emphasizes the depolarization dependency of augmentation in this type of incremental responses.

Last, we investigated the persistent effects produced by pulse trains at $10 \mathrm{~Hz}$, repeated every $2-3 \mathrm{sec}(n=8)$. Figure 10 illustrates the evolution of augmenting responses elicited by successive pulse trains at $10 \mathrm{~Hz}$, delivered every $2 \mathrm{sec}$, under steady depolarization $\left(+0.5 \mathrm{nA},-60 \mathrm{mV}\right.$; resting $\mathrm{V}_{\mathrm{m}}$ was $\left.-72 \mathrm{mV}\right)$. Data demonstrate a progressive and persistent increase in the area under the depolarizing response from the first to the fifth stimuli in a train and from the initial to following pulse trains (Fig. 10, 1-4). The area of depolarization increased at the expense of IPSPs, which eventually disappeared (Fig. 10, compare responses in sequences 1,2 with those in sequences 3,4). This increase in the depolarization area was of about $500 \%$ from the first to the fifth stimuli in pulse train 1, 270\% in train 2, and $150 \%$ in the last trains (trains 3 and 4); also, the area of depolarization in the response to the second stimulus in the last pulse trains 3 and 4 increased by about $800 \%$ compared with the already augmented response elicited by the second stimulus in pulse train 1 .

\section{Intrathalamic augmenting responses from low- threshold rebound responses}

In contrast to the majority of VL cells that showed augmentation developing at relatively depolarized levels during decreasing inhibition, 57 neurons (38\% of all intracellularly recorded VL neurons) displayed incremental responses consisting of LT responses on a background of increasing hyperpolarization, reaching -72 to $-78 \mathrm{mV}$ at the third to fifth stimuli in a pulse train at $10 \mathrm{~Hz}$. Commonly, after the LT-type augmenting evoked by thalamic stimuli, a spindle sequence $(7-8 \mathrm{~Hz})$ outlasted the pulse train, with rhythmic IPSPs and LT responses occasionally leading to high-frequency rebound bursts (see cell VL2 in Fig. 11).

The different features of augmenting responses in the two groups of VL cells could also be demonstrated when two neurons were recorded simultaneously. The dual, simultaneous impalements illustrated in Figure 11 show different resting $\mathrm{V}_{\mathrm{m}}$ values in the two (VL1 and VL2) neurons. VL1 neuron, at a relatively depolarized $\mathrm{V}_{\mathrm{m}}$, fired spontaneously before as well as after the pulse train at $10 \mathrm{~Hz}$ that evoked augmenting responses consisting of doublets with interspike intervals of $6.5-7.5 \mathrm{msec}$. The simultaneously recorded VL2 neuron was silent in periods free of stimuli and displayed augmenting responses on a background of increasing hyperpolarization that were eventually crowned by spike bursts with interspike intervals shorter than 2.5-4 msec, typical for LT-elicited bursts. And whereas the VL1 cell recovered its prestimulation state quickly after the pulse train, the VL2 cell oscillated for $1.5 \mathrm{sec}$, within the spindle frequency, after the pulse train.

The similarity between the LT-type of intrathalamic augmenting and the spindle oscillations consisting of rhythmic IPSP-LT sequences, as well as the demonstration that spindle-related hyperpolarizations are $\mathrm{GABA}_{\mathrm{A}}$-dependent IPSPs (Deschênes et al., 1984; Bal et al., 1995a), suggested that similar events underlie the two phenomena (spindle and LT-type augmenting) and prompted 


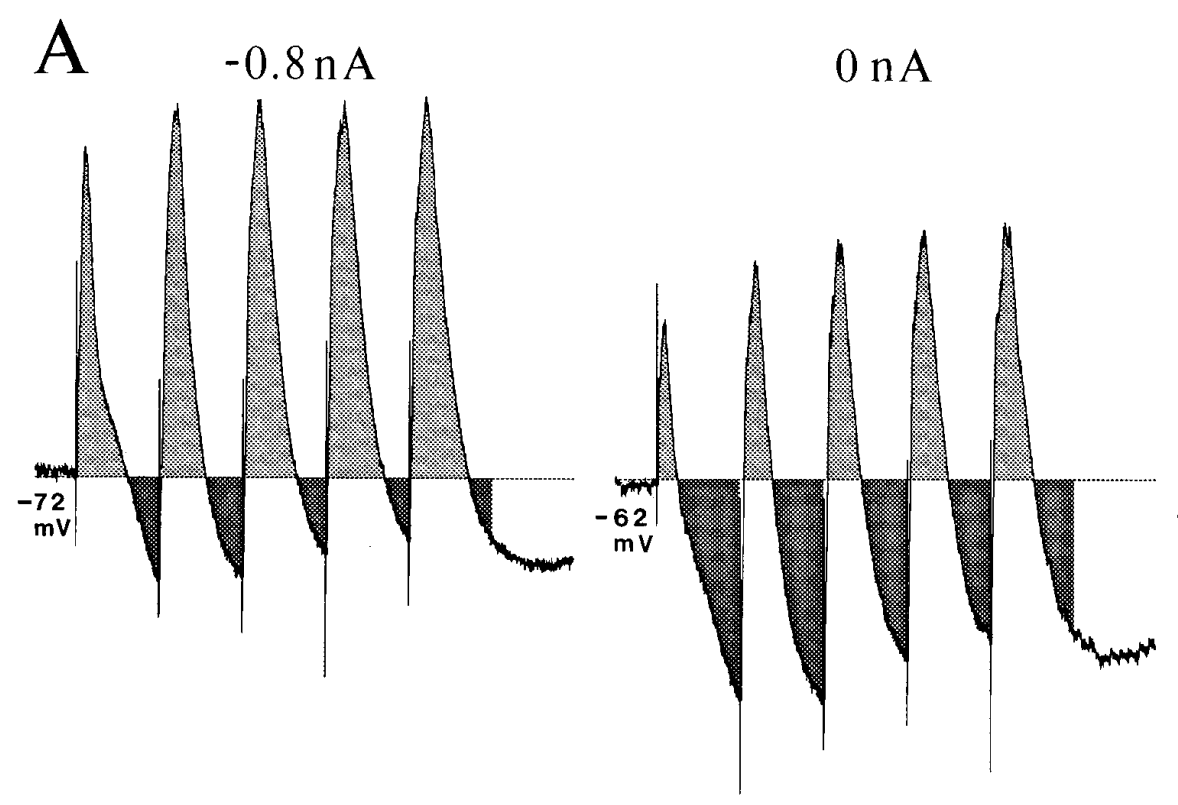

onA

$+0.8 \mathrm{nA}$
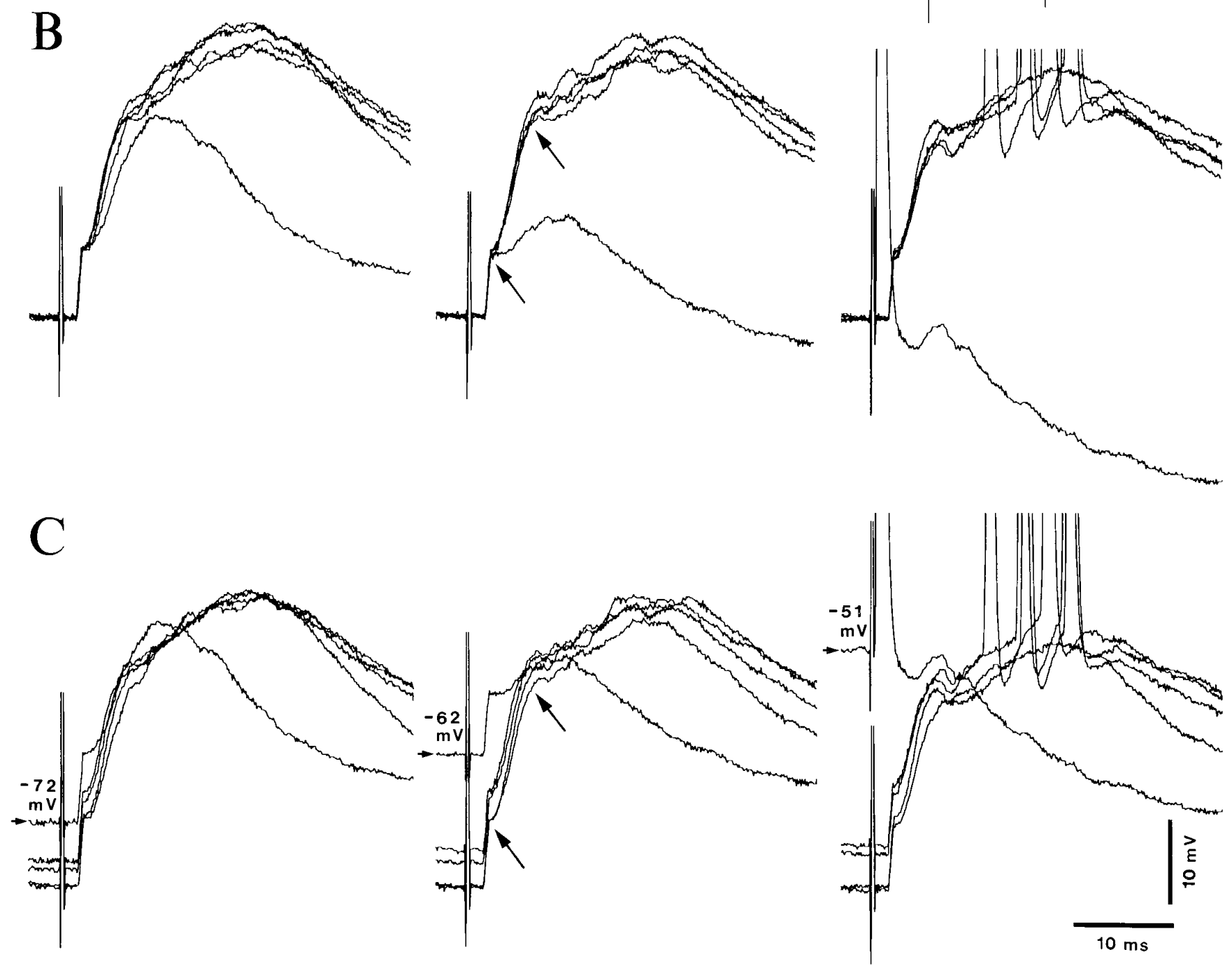
us to study the effects of $\mathrm{Cl}^{-}$infusion into neurons displaying spontaneously occurring spindles and thalamic evoked augmenting responses in ipsilaterally decorticated animals $(n=7)$. Immediately after impalement with KCl-filled micropipettes, spontaneously occurring spindles or spindles evoked by single stimuli to the VL nucleus consisted of hyperpolarizing IPSPs, whereas VL stimuli at $10 \mathrm{~Hz}$ elicited augmenting waves of the LT type, continuing with a self-sustained spindle sequence formed by hyperpolarizing IPSPs (Fig. 12, top trace). Eight and $30 \mathrm{~min}$ after intracellular infusion of $\mathrm{Cl}^{-}$(Fig. 12, middle and bottom traces), the spindlerelated IPSPs became depolarizing and eventually triggered bursts of action potentials, and the augmenting responses as well as the ensuing spindles were also depolarizing. Thus, both the evoked augmenting responses and the self-sustained spindle sequences displayed mirror images when examined before $(2 \mathrm{~min})$ and $8-30$ min after $\mathrm{Cl}^{-}$infusion (see expanded traces, $2 \mathrm{~min}$ and $8 \mathrm{~min}$ after impalement; Fig. 12, arrows).

\section{DISCUSSION}

Three major findings come from our experiments: (1) augmenting responses can be generated within the thalamus, without necessarily involving reverberating corticothalamic loops; (2) the intrathalamic incremental potentials occur at relatively depolarized levels in association with decreasing IPSPs, or alternatively, they may develop as LT responses deinactivated by increasing membrane hyperpolarization; and (3) by repeating the pulse trains, augmenting responses progressively and persistently increase the area of cell depolarization, whereas the IPSPs display a progressive diminution in their amplitudes. The frequency-dependent augmentation of intrathalamic responses is the first step toward the demonstration of short-term plasticity at the thalamic gateway to the cerebral cortex.

\section{Structures activated by intrathalamic stimulation}

By stimulating the VL nucleus, close to the impaled neurons, we might have activated a series of fiber systems as well as local GABAergic interneurons, which are present in virtually all dorsal thalamic nuclei of cats and primates, including the VL (Jones, 1985; Hunt et al., 1991; Spreafico et al., 1993). Among many afferent systems to VL neurons, the cerebellothalamic axons were most likely those that produced the EPSPs, giving rise to action potentials and followed by a prolonged, biphasic IPSP (Figs. 2-4), because similar intracellular VL responses were elicited by stimulating deep cerebellar nuclei; however, repetitive stimulation of the cerebellothalamic pathway did not produce augmenting responses (unpublished data). The activation within the VL nucleus of other excitatory fiber systems, originating in the spinal cord and brainstem tegmentum (see Jones, 1985) or more medial thalamic nuclei (Purpura, 1970) is also possible. As to the involvement of corticothalamic fibers, besides their possible degeneration after the removal of cortex and white matter up to a few millimeters from the thalamus (see Fig. 1), the state of TC neurons suggests that a few hours after decortication, corticothalamic axons were no longer functional. Indeed, the same VL neuron exhibited spindles shortly after decortication, but $2 \mathrm{hr}$ later the $7-8 \mathrm{~Hz}$ rhythmic IPSPs were changed into a hyperpolarization-activated delta oscillation $(1-4 \mathrm{~Hz})$ as a result of the removal of the depolarizing impingement from corticothalamic axons (see Timofeev and Steriade, 1996, their Fig. 12). Even if corticothalamic axons were still functional at the time of recording, augmenting responses were fully expressed in the absence of intact thalamocorticothalamic loops. The augmentation of corticothalamic responses is inhibited by administration of ketamine, thus leading to the conclusion that this synaptic increment is mediated by the activation of NMDA receptors (Deschênes and $\mathrm{Hu}, 1990)$. This is at variance with the resistance of intrathalamic augmenting responses to ketamine anesthesia in the present experiments.

The LT-type augmenting, resulting from increasing hyperpolarization during repetitive stimulation at $10 \mathrm{~Hz}$, is probably a result of activation of GABAergic inhibitory neurons, RE, and local circuit cells. Despite the demonstration that prolonged, biphasic (Crunelli et al., 1988), or triphasic (Paré et al., 1991) IPSPs can be elicited in TC cells by local interneurons in the absence of RE afferents, several points indicate that thalamic stimulation elicited augmenting responses stemming from postinhibitory rebound phenomena as a result of activation of RE cells, rather than local circuit cells. The activation of local interneurons by recurrent collaterals of TC axons is precluded by the absence of such intranuclear collaterals in intracellularly stained neurons of VL (Steriade and Deschênes, 1984; Sawyer et al., 1994) and other principal nuclei of the dorsal thalamus (Yen and Jones, 1983; Kita and Kitai, 1986; Liu et al., 1995). Dual intracellular recordings from VL and lateroposterior (LP) thalamic neurons in decorticated animals show that repetitive stimuli applied to either the VL or LP nucleus may elicit LT-type augmenting responses in simultaneously recorded VL and LP neurons (unpublished data). This suggests that common pools of rostrolateral RE neurons, with divergent projections to the dorsal thalamus, underlie the IPSPs from which incremental responses arise in VL and LP cells but discards the direct activation of local circuit cells in these thalamic nuclei. Because augmenting arising from LT responses looks similar to spindle oscillations, we also mention that intracellular $\mathrm{Cl}^{-}$ infusion blocked augmenting as well as spontaneously occurring and evoked spindles (Fig. 12). Whereas RE neurons have a decisive role in the genesis and synchronization of spindles, local circuit cells do not trigger spindle-related, rhythmic IPSPs and rebound spike bursts in TC cells (Steriade et al., 1985; Bal et al., 1995a).

\footnotetext{
$\leftarrow$

Figure 7. Intrathalamic augmenting potentials developing in parallel with progressively decreased hyperpolarizations. $A$, A TC cell from a VL nucleus was tested with trains of five stimuli at $10 \mathrm{~Hz}$ under steady hyperpolarizing current $(-0.8 \mathrm{nA})$ (left), at rest $(0 \mathrm{nA})$ (middle), and under steady depolarizing current $(+0.8 \mathrm{nA})($ right $)$. Superimposed responses were offset at the initial $\mathrm{V}_{\mathrm{m}}$ (see real $\mathrm{V}_{\mathrm{m}} \mathrm{s}$ in $C$ ). B, Superimposed and expanded early responses $($ at the same $\mathrm{V}_{\mathrm{m}}$, as in $A$ ). The bottom arrow in the middle column tentatively indicates the level where the initial EPSP gave rise to an LT response, whereas the top arrow marks the inflection where augmenting responses were initiated at a more depolarized level. Note action potentials triggered by the augmented response under $+0.8 \mathrm{nA}$ (right column). $C$, The early responses were superimposed and expanded but shown at the real $\mathrm{V}_{\mathrm{m}}$. In all superimpositions, the response to the first stimulus in the train is at the indicated $\mathrm{V}_{\mathrm{m}}(-72 \mathrm{mV}$ under $-0.8 \mathrm{nA},-62 \mathrm{mV}$ without current, and $-51 \mathrm{mV}$ under $+0.8 \mathrm{nA}$ ). The next two traces illustrate the responses to the fifth and fourth stimuli, and the last traces represent responses to the second and third stimuli. Note, under $+0.8 \mathrm{nA}$, the antidromic spike immediately after the first stimulus in the train at $-51 \mathrm{mV}$ but its blockage at more hyperpolarized levels.
} 

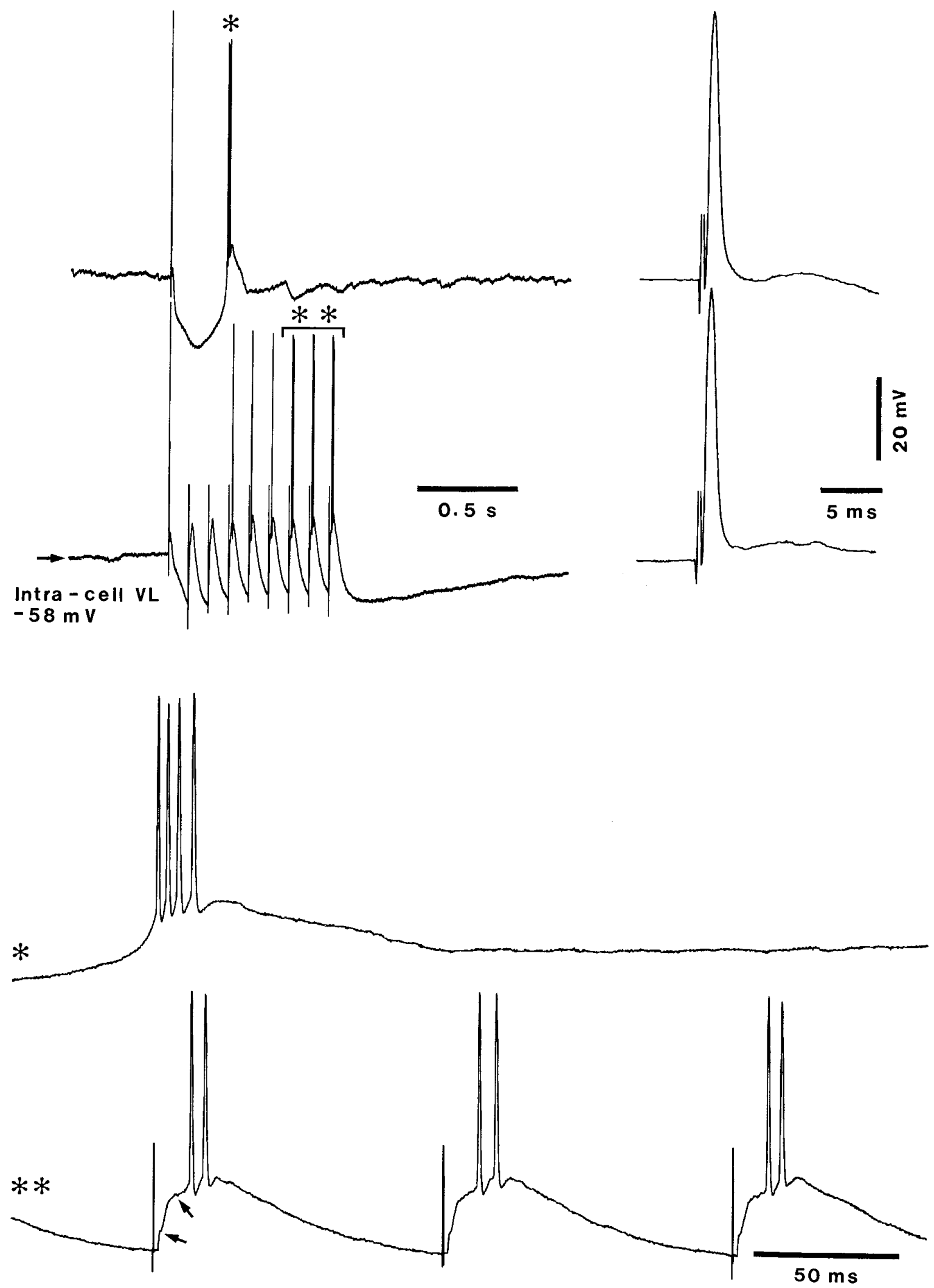

Figure 8. Augmenting responses on the top of LT responses. Top, Response to a single VL stimulus ( first trace) and responses to a nine-shock train (second trace). The early, antidromic responses are expanded at right. Bottom, The postinhibitory rebound burst to the single stimulus $(*)$ and the last three responses to the nine-shock train $(* *)$ are expanded below. The first arrow in the bottom trace indicates the level where the EPSP gave rise to an LT response, and the second arrow marks the inflection where the secondary component of the augmenting response arose at a more depolarized level. Note the difference between the pattern of spike burst crowning the LT response in the postinhibitory rebound to the single stimulus $(*)$ and the doublets in the augmented responses $(* *)$. 

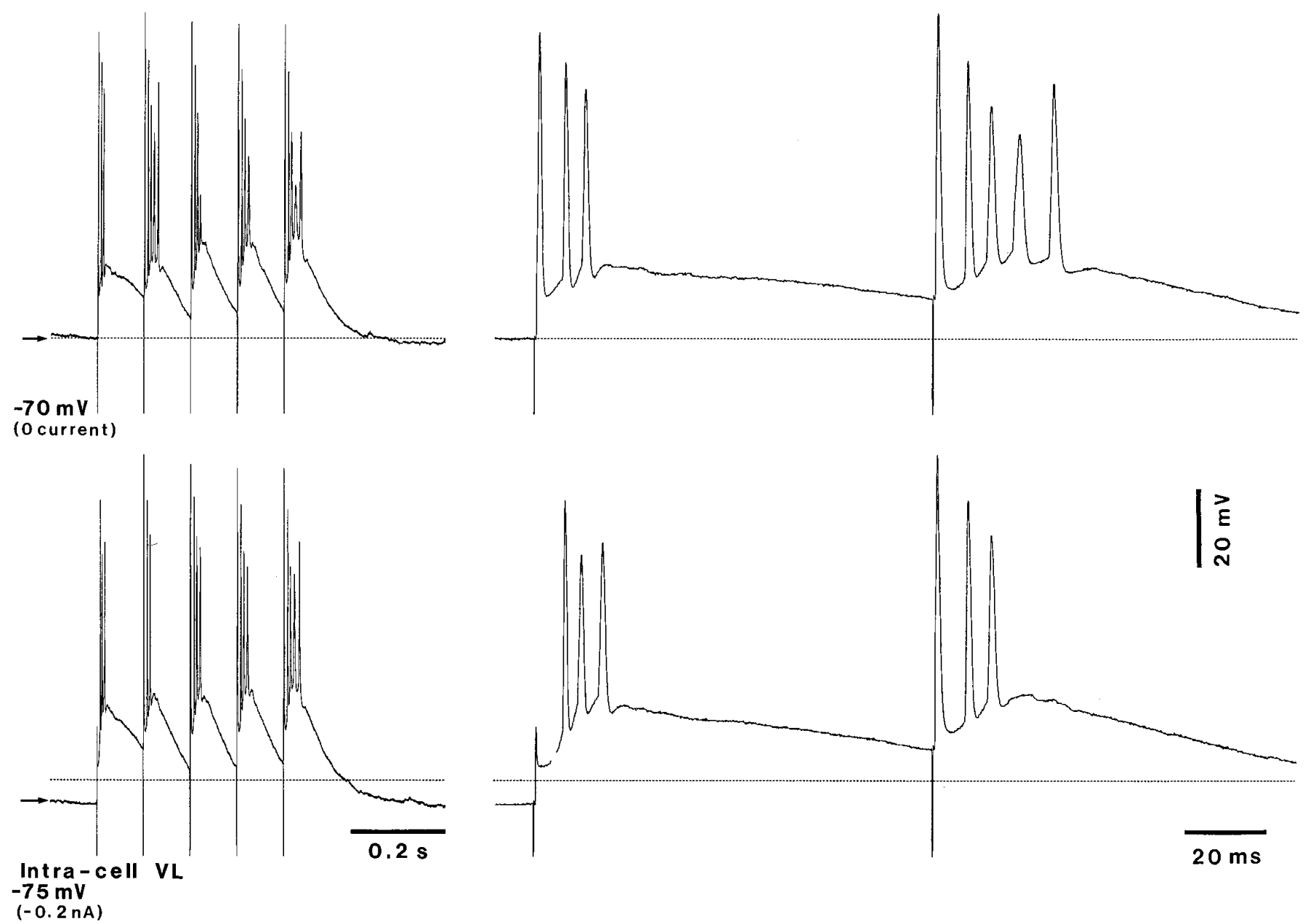

$(-0.2 \mathrm{nA})$

Figure 9. Reduction of the number of spikes in the second augmented response at hyperpolarized levels. Five stimuli at $10 \mathrm{~Hz}$ were applied at rest ( -70 $\mathrm{mV}$ ) and under steady hyperpolarization $(-0.2 \mathrm{nA},-75 \mathrm{mV}$ ). Responses to first two stimuli in the train are expanded at right (responses consist of an initial antidromic spike, followed by two to four orthodromic spikes). Note, at the hyperpolarized level, transformation of the full antidromic spike into an initial segment spike.

\section{Genesis of intrathalamic augmenting responses}

In the majority of neurons $(62 \%)$, augmenting resulted from responses evolving in parallel with progressively decreased IPSPs (Figs. 3-5). About one-half of those TC cells gave rise to incremental responses on the top of LT potentials produced during the hyperpolarizing phase of the response triggered by the preceding stimulus in the pulse train (see these steps illustrated by two arrows in Figs. 7, 8). The synaptically induced progression in the present experiments is reminiscent of a similar step resulting from application of current pulses in thalamic slices (Jahnsen and Llinás, 1984). This was not the exclusive mechanism for the generation of incremental responses, because in the remaining TC cells, augmentation of spike bursts occurred during the depolarization produced by an antidromic action potential, without an intermediate IPSP that would have promoted the deinactivation of an LT response (Figs. 3, 4).

The augmented responses of TC cells occurring at a relatively depolarized level may be ascribed, at least partially, to a highthreshold (HT) $\mathrm{Ca}^{2+}$ conductance in view of putative intradendritic recordings in vitro (Jahnsen and Llinás, 1984) and in vivo (Roy et al., 1984), revealing a voltage-dependent HT conductance triggering all-or-none depolarizing responses, followed by the activation of a $\mathrm{g}_{\mathrm{K}(\mathrm{Ca})}$. Some of the fast prepotentials (FPPs) in thalamic cells
(Maekawa and Purpura, 1967; Deschênes et al., 1984; Paré et al., 1989; Steriade et al., 1991b) probably represent dendritic spiking that dominates the behavior of the cell when somatic $\mathrm{Na}^{+}$channels are blocked by intracellular injections of QX-314 (Mulle et al., 1985). In the present experiments, the progressive increase in presumed HT responses during intrathalamic augmenting was associated with decreasing IPSPs of TC cells (Figs. 7, 10). Disinhibition also causes enhanced signal transmission in the dentate gyrus when stimuli are delivered between 2.5 and $10 \mathrm{~Hz}$ (Mott et al., 1993). In the auditory cortex too, the enhancement of late EPSPs produced by paired-pulse (200 msec intervals) stimulation was a result of release from GABAergic IPSPs (Metherate and Ashe, 1994). Paired-pulse facilitation may be ascribed to decreases in GABA release by presynaptic activation of $\mathrm{GABA}_{\mathrm{B}}$ receptors, as found in neocortical (Deisz and Prince, 1994) as well as in TC and RE neurons (Soltesz and Crunelli, 1992; Uhlrich and Huguenard, 1996). Although in one-half of neurons the augmenting developed in association with the depression of IPSPs, in the remaining neurons this form of augmenting developed immediately after the antidromic spike, which depolarized the cell to the level required for the appearance of HT-augmented responses without an intermediate step involving the IPSP, leading to an LT response (Figs. 4, pulse train 2, and 10).

We interpret the two types of thalamic augmentation resulting 


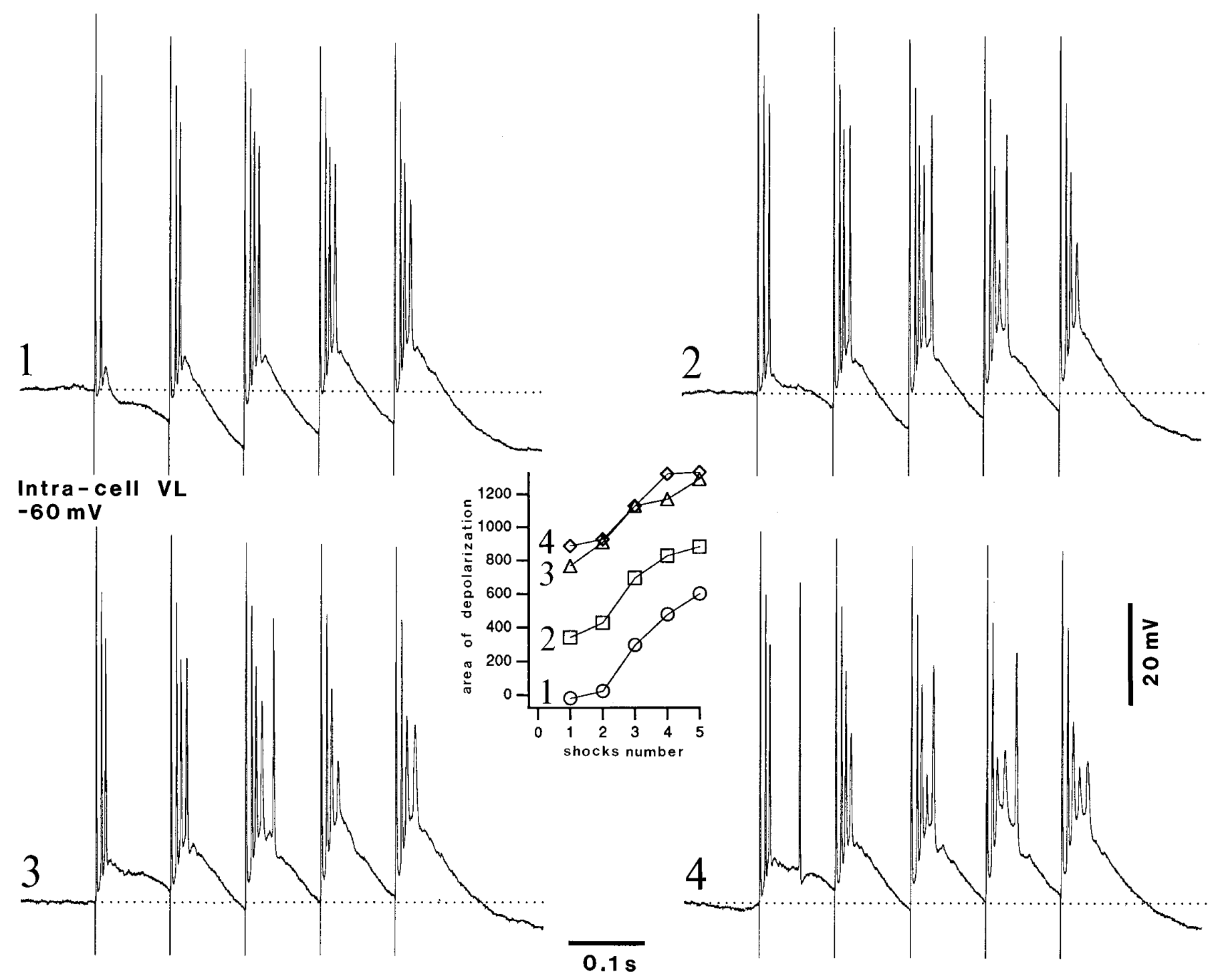

Figure 10. Progressive and persistent increase in the area of depolarization during augmenting responses by repeating the pulse trains. The VL cell was recorded at different $\mathrm{V}_{\mathrm{m}}$ values while pulse trains $(10 \mathrm{~Hz}$, same intensity) were applied to the VL every 2 sec. The cell was recorded under $+0.5 \mathrm{nA}(-60$ $\mathrm{mV}$ ); at rest, $\mathrm{V}_{\mathrm{m}}$ was $-72 \mathrm{mV}$. Responses to four successive pulse trains (1-4) are illustrated ( 1 and 2 were separated by 2 sec; 3 and 4 were also separated by $2 \mathrm{sec}$ and followed $14 \mathrm{sec}$ after 2). Note that, with repetition of pulse trains, IPSPs elicited by preceding stimuli in the train were progressively reduced until their complete obliteration and spike bursts contained more action potentials with spike inactivation. The graph depicts the increased area of depolarization from the first to the fifth responses in each pulse train as well as from pulse train 1 to pulse trains 3 and 4 .

from factors related to membrane properties of TC cells and their place in the synaptic circuitry of the thalamus. At a relatively hyperpolarized levels, LT responses built up the increment. The increased number of discharges of cells to the second thalamic stimulus at a time interval of $100 \mathrm{msec}$, reported in extracellular recordings (Schlag and Villablanca, 1968), is now explained by the powerful IPSP produced by the first stimulus, thus deinactivating LT $\mathrm{Ca}^{2+}$ channels and promoting high-frequency bursting. As to the augmenting responses elicited under depolarization (about -55 to $50 \mathrm{mV}$ ), at a $\mathrm{V}_{\mathrm{m}}$ level at which the LT channels are largely inactivated, we speculate that such responses partially represent HT responses, although they probably represent an aggregate resulting from the relative combination of EPSPs and LT and HT responses. The following scenario is speculative, but it can be tested in future in vitro and modeling studies. The increased EPSPs, as a result of the hyperpolarization produced by the late IPSP elicited by the first stimulus in the $10 \mathrm{~Hz}$ pulse train, gives rise to an LT response; the latter, together with the EPSPs set into action by local stimulation, may depolarize some sectors of the dendritic arbor and thus activate an HT conductance. The variable HT or LT responses of TC cells depend on the subtle balance between the depolarizing impingement from different excitatory afferent systems and the summated actions of inhibitory RE neurons acting on TC cells. Data from parallel experiments in which we performed dual intracellular recordings of TC cells from LP and VL nuclei demonstrate that the closer the electrodes activating TC cells, the greater the proportion of presumed HT responses (unpublished observations). The predominant IPSPs, giving rise to augmentation from LT responses, are presumably a result of drives from pools of RE neurons that are implicated by testing stimuli and overwhelm the excitatory afferents. In parallel experiments (Steriade and Timofeev, 1996), we found two populations of RE neurons exhibiting incremental or decremental responses, depending on the parameters of repetitive dorsal tha- 

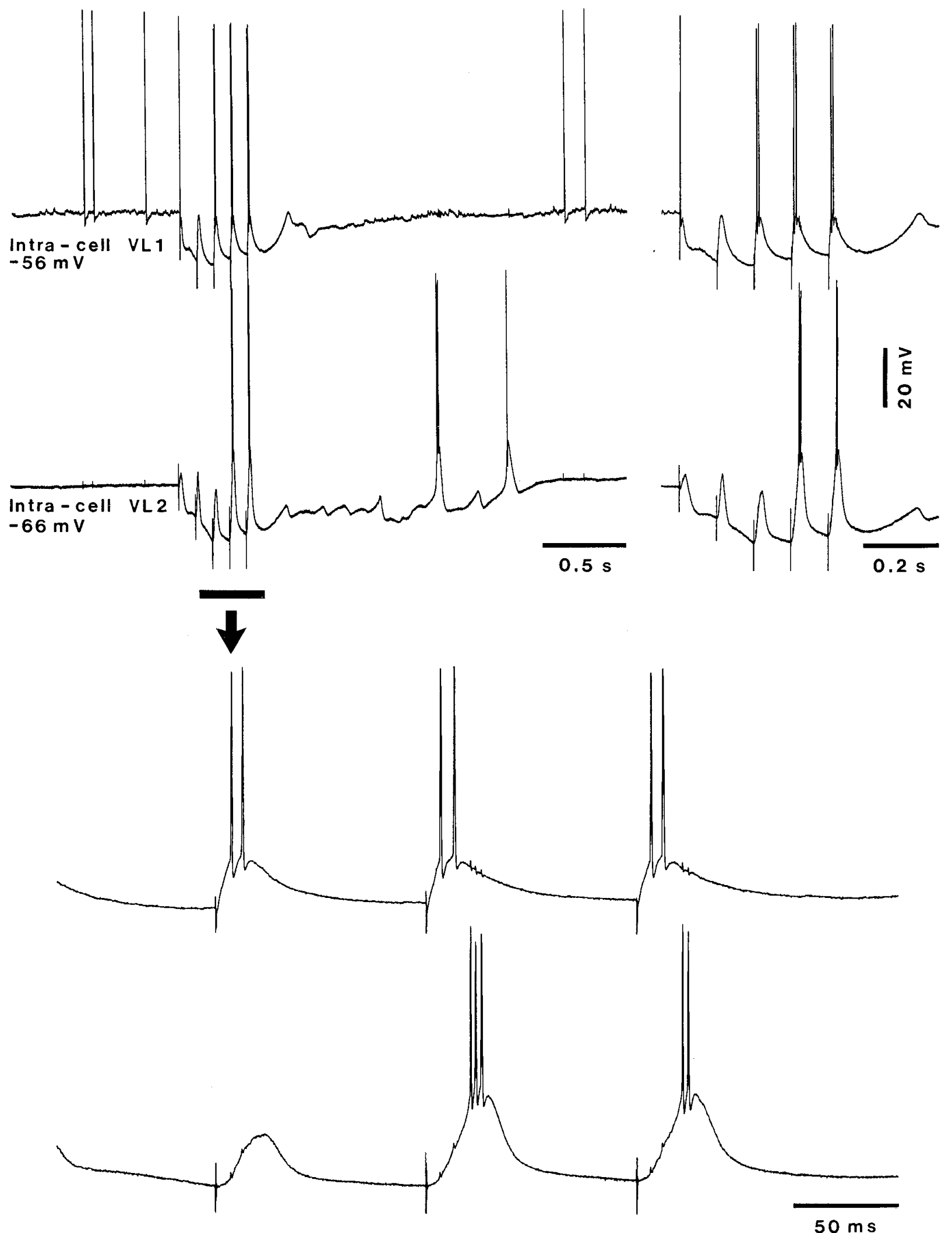

Figure 11. Different features of augmenting responses at hyperpolarized and depolarized levels. Simultaneous dual intracellular recordings of TC cells from VL nucleus. Cell 1 was recorded at a more depolarized $\mathrm{V}_{\mathrm{m}}(-56 \mathrm{mV})$ than cell $2(-66 \mathrm{mV})$. Accordingly, before and after augmenting responses cell 1 discharged single spikes, whereas cell 2 displayed after augmenting responses a spindle sequence eventually leading to rebound spike bursts. Right, Expanded responses to the five stimuli in the train at $10 \mathrm{~Hz}$. The last three responses in the train (horizontal bar) are further expanded below (arrow). Note short-latency incremental responses consisting of spike doublets in cell 1, the patterns of which are quite different from the longer latency LTSs crowned by spike bursts in cell 2 . Small deflections in each of two cells are a result of capacitive coupling from action potentials of the other neuron. 


\section{$2 \mathrm{~min}$}
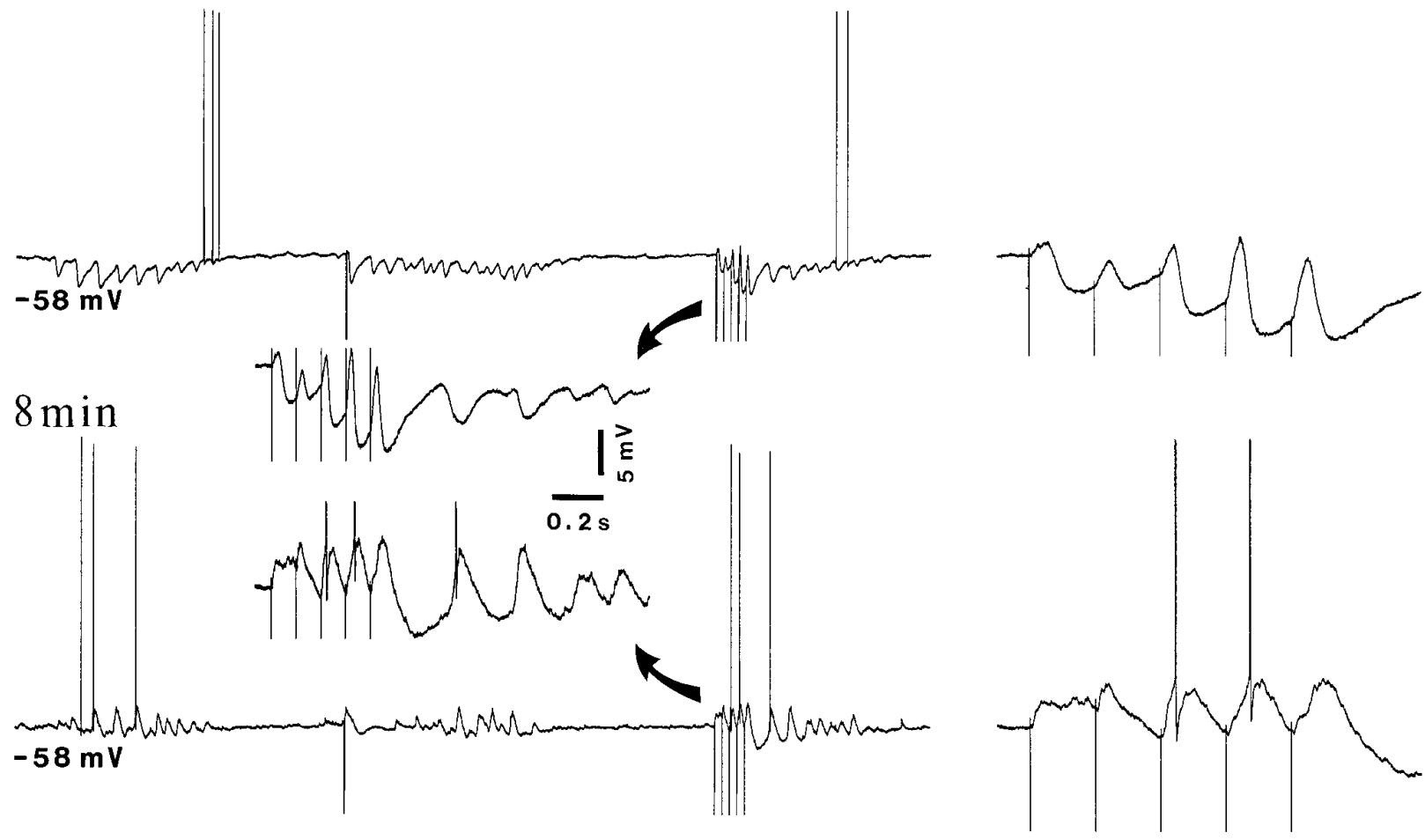

\section{$30 \mathrm{~min}$}

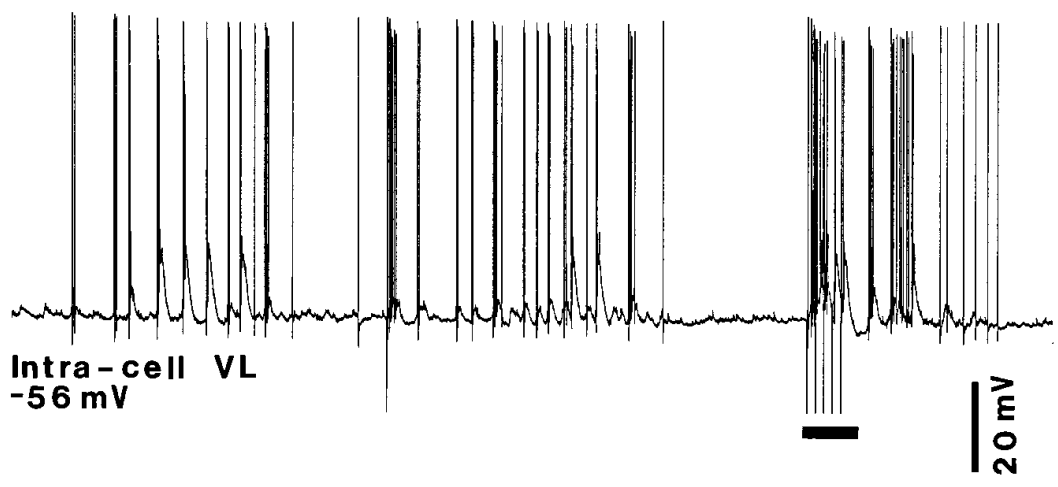

$1 \mathrm{~s}$

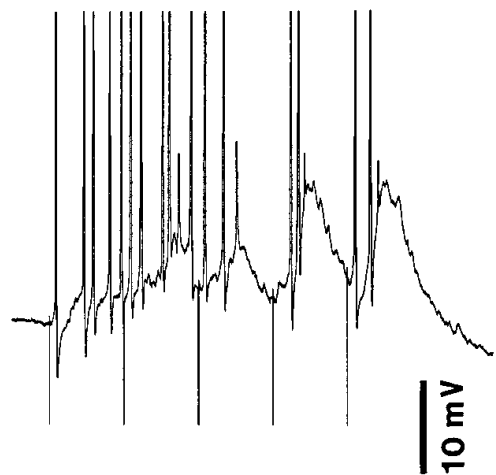

$\overline{0.1 \mathrm{~s}}$

Figure 12. Intracellular $\mathrm{Cl}^{-}$infusion reverses spindle-related IPSPs and transforms LT-type augmenting into depolarizing incremental responses. Recording with a micropipette filled with K-acetate $(1 \mathrm{M})$ and $\mathrm{KCl}(2 \mathrm{M})$. Shortly $(2 \mathrm{~min})$ after impaling, a spontaneously occurring spindle $($ left $)$ and spindle evoked by single-shock VL stimulus (middle) consisted of rhythmic IPSPs, and augmenting responses evoked by a pulse train (10 Hz) to VL were of the LT type, over a background of increased hyperpolarization. After $\mathrm{Cl}^{-}$infusion ( 8 and $30 \mathrm{~min}$ ), spindles and incremental responses were depolarizing. Augmenting responses at 2 and $8 \mathrm{~min}$ are expanded (two arrows) to show the mirror images of spindles outlasting the pulse train at $10 \mathrm{~Hz}$. Right, Expanded augmenting responses to 5 VL stimuli (period marked by horizontal bar at 30 min; spikes truncated at 8 and 30 min).

lamic volleys. We propose that incremental responses in RE cells produce augmenting that develops from LT responses as a result of a progressive hyperpolarization in TC cells, whereas decremental responses in RE cells, attributable to intra-RE inhibitory processes (see Huguenard and Prince, 1994; Uhlrich and Huguenard, 1996), would lead to disinhibition in target TC cells.

Similarly to the thalamic augmentation in decorticated animals reported here, a progressive depolarization occurs in cortical neurons of athalamic animals in responses to rhythmic cortical stimuli at $10 \mathrm{~Hz}$, leading to continuously increased augmenting responses (see Steriade et al., 1993b, their Fig. 14). More complex pictures would be expressed in intact cortex preparations where thalamic neurons are embedded within corticothalamic circuits. Here, we have demonstrated progressive and persistent change in the functional state of thalamic neurons, related to both excitatory (Figs. 3, 10) and inhibitory (Fig. 6) processes that may subserve short-term plasticity, influencing the processing of incoming signals. In vivo, the thalamic augmenting responses can play an important role in the generation of late cortical EPSPs, the enhancement of which is produced by paired stimuli within the frequency range of 5-15 Hz (Metherate and Ashe, 1994; CastroAlamancos and Connors, 1996a-c). These changes are likely 
dependent on the behavioral state of vigilance. In the cortex, augmenting responses in motor and somatosensory thalamocortical systems are diminished during strong behavioral or brainstem-induced arousal (Steriade et al., 1969; Steriade and Morin, 1981; Castro-Alamancos and Connors 1996a). On the other hand, TC neurons display an enhanced responsiveness after a brief pulse train to the activating mesopontine cholinergic neurons (Timofeev et al., 1996), and this brainstem-thalamic potentiation may be prolonged up to 4 min (Paré et al., 1990).

We conclude that both the thalamus and the cerebral cortex have the necessary equipment to develop augmenting responses, but when these structures are interconnected the augmentation is facilitated by thalamic-generated spike bursts transmitted to the cortex, as well as by incremental potentials in the reciprocal corticothalamic pathway. In intact cortex animals, augmenting responses may develop into self-sustained seizures with spikewave complexes (SWs) at 2-4 Hz, lasting for 10-20 sec, occurring in the motor cortex of monkeys (Steriade, 1974) and somatosensory cortex of cats (Steriade and Yossif, 1974) after repetitive stimulation of related thalamic nuclei. Also, self-sustained SW seizures follow augmenting responses in the thalamus after application of repeated pulse trains at $10 \mathrm{~Hz}$ to cortical areas (Steriade et al., 1976). In the present experiments on decorticated animals, we did not obtain such paroxysmal developments, thus suggesting that plasticity processes underlying the transformation of incremental responses into self-sustained seizures require the presence of intact thalamocorticothalamic loops.

\section{REFERENCES}

Andersen P, Andersson S (1968) Physiological basis of alpha rhythm. New York: Appleton.

Bal T, von Krosigk M, McCormick DA (1995a) Synaptic and membrane mechanisms underlying synchronized oscillations in the ferret lateral geniculate nucleus in vitro. J Physiol (Lond) 483:641-663.

Bal T, von Krosigk M, McCormick DA (1995b) Role of ferret perigeniculate nucleus in the generation of synchronized oscillations in vitro. J Physiol (Lond) 483:665-685.

Castro-Alamancos MA, Connors BW (1996a) Short-term plasticity of a thalamocortical pathway dynamically modulated by behavioral state. Science 272:274-277.

Castro-Alamancos MA, Connors BW (1996b) Spatiotemporal properties of short-term plasticity in sensorimotor thalamocortical pathways of the rat. J Neurosci 16:2767-2779.

Castro-Alamancos MA, Connors BW (1996c) Cellular mechanisms of the augmenting response: short-term plasticity in a thalamocortical pathway. J Neurosci 16:7742-7756.

Contreras D, Steriade M (1996) Spindle oscillations in cats: the role of corticothalamic feedback in a thalamically generated rhythms. J Physiol (Lond) 490:159-180.

Contreras D, Destexhe A, Sejnowski TJ, Steriade M (1996) Control of spatiotemporal coherence of a thalamic oscillation by corticothalamic feedback. Science 274:771-774.

Crunelli V, Haby M, Jassik-Gerschenfeld D, Leresche N, Pirchio M (1988) $\mathrm{Cl}^{-}$and $\mathrm{K}^{+}$dependent inhibitory postsynaptic potentials evoked by interneurons of the rat lateral geniculate nucleus. J Physiol (Lond) 399:153-176.

Deisz RA, Prince DA (1989) Frequency-dependent depression of inhibition in guinea-pig neocortex in vitro by $\mathrm{GABA}_{\mathrm{B}}$ receptor feedback on GABA release. J Physiol (Lond) 412:513-544.

Deschênes M, Hu B (1990) Electrophysiology and pharmacology of the corticothalamic input to lateral thalamic nuclei: an intracellular study in the cat. Eur J Neurosci 2:140-152.

Deschênes M, Paradis M, Roy JP, Steriade M (1984) Electrophysiology of neurons of lateral thalamic nuclei in cat: resting properties and burst discharges. J Neurophysiol 51:1196-1219.

Ferster D, Lindström S (1985) Augmenting responses evoked in area 17 of the cat by intracortical axonal collaterals of cortico-geniculate cells. J Physiol (Lond) 367:217-232.

Hirsch JC, Burnod Y (1987) A synaptically evoked late hyperpolarization in the rat dorsolateral geniculate neurons in vitro. Neuroscience 23:457-468.

Huguenard JR, Prince DA (1994) Clonazepam suppresses GABA $_{\mathrm{B}^{-}}$ mediated inhibition in thalamic relay neurons through effects in nucleus reticularis. J Neurophysiol 71:2576-2581.

Hunt CA, Pang DZ, Jones EG (1991) Distribution and density of GABA cells in intralaminar and adjacent nuclei of monkey thalamus. Neuroscience 43:185-196.

Jahnsen H, Llinás R (1984) Ionic basis for the electroresponsiveness and oscillatory properties of guinea-pig thalamic neurones in vitro. J Physiol (Lond) 349:227-247.

Johnston D, Wu SMS (1995) Foundations of cellular neurophysiology. Cambridge, MA: Bradford.

Jones EG (1985) The thalamus. New York: Plenum.

Kita H, Kitai ST (1986) Electrophysiology of rat thalamocortical relay neurons: an in vivo intracellular recording and labeling study. Brain Res 371:80-89.

Liu XB, Warren RA, Jones EG (1995) Synaptic distribution of afferents from reticular nucleus in ventroposterior nucleus of cat thalamus. J Comp Neurol 352:187-202.

Maekawa K, Purpura DP (1967) Intracellular study of lemniscal and non-specific synaptic interactions in thalamic ventrobasal neurons. Brain Res 4:308-323.

McCormick DA, Pape HC (1988) Acetylcholine inhibits identified interneurons in the cat lateral geniculate nucleus. Nature 334:246-248.

McCormick DA, Pape HC (1990) Properties of a hyperpolarizationactivated cation current and its role in rhythmic oscillation in thalamic relay neurones. J Physiol (Lond) 431:291-318.

Metherate R, Ashe JH (1994) Facilitation of an NMDA receptormediated EPSP by paired-pulse stimulation in rat neocortex via depression of GABAergic IPSP. J Physiol (Lond) 481:331-348.

Morin D, Steriade M (1981) Development from primary to augmenting responses in primary somatosensory cortex. Brain Res 205:49-66.

Morison RS, Bassett DL (1945) Electrical activity of the thalamus and basal ganglia in decorticated cats. J Neurophysiol 8:309-314.

Morison RS, Dempsey EW (1942) A study of thalamocortical relations. Am J Physiol 135:281-292.

Morison RS, Dempsey EW (1943) Mechanism of thalamocortical augmentation and repetition. Am J Physiol 138:297-308.

Mott DD, Xie CW, Wilson WA, Swartzwelder HS, Lewis DV (1993) $\mathrm{GABA}_{\mathrm{B}}$ autoreceptors mediate activity-dependent disinhibition and enhance signal transmission in the dentate gyrus. J Neurophysiol 69:674-691.

Mulle C, Steriade M, Deschênes M (1985) The effects of QX314 on thalamic neurons. Brain Res 333:350-354.

Nuñez A, Amzica F, Steriade M (1993) Electrophysiology of cat association cortical cells in vivo: intrinsic properties and synaptic responses. J Neurophysiol 70:418-430.

Pape HC, McCormick DA (1995) Electrophysiological and pharmacological properties of interneurons in the cat dorsal lateral geniculate nucleus. Neuroscience 68:1105-1125.

Paré D, Steriade M, Deschênes M, Bouhassira D (1990) Prolonged enhancement of anterior thalamic synaptic responsiveness by stimulation of a brainstem cholinergic group. J Neurosci 10:20-23.

Paré D, Curró Dossi R, Steriade M (1991) Three types of inhibitory postsynaptic potentials generated by interneurons in the anterior thalamic complex of cat. J Neurophysiol 66:1190-1204.

Purpura DP (1970) Operations and processes in thalamic and synaptically related neural systems. In: The neurosciences, second study program (Schmitt FO, ed), pp 458-470. New York: Rockefeller University.

Room P, Groenewegen HJ (1986) Connections of the parahippocampal cortex in the cat. II. Subcortical afferents. J Comp Neurol 251:451-473.

Roy JP, Clercq M, Steriade M, Deschênes M (1984) Electrophysiology of neurons of the lateral thalamic nuclei in cat: mechanisms of long-lasting hyperpolarizations. J Neurophysiol 51:1220-1235.

Sawyer SF, Tepper JM, Groves PM (1994) Cerebellar-responsive neurons in the thalamic ventroanterior-ventrolateral complex of rats: light and electron microscopy. Neuroscience 63:725-745.

Schlag J, Villablanca J (1968) A quantitative study of temporal and spatial response patterns in a thalamic cell population electrically stimulated. Brain Res 8:255-270.

Soltesz I, Crunelli V (1992) GABA $_{A}$ and pre- and post-synaptic GABA receptor-mediated responses in the lateral geniculate nucleus. Progr Brain Res 90:151-169.

Soltesz I, Lightowler S, Leresche N, Jassik-Gerschenfeld D, Pollard CE, 
Crunelli V (1991) Two inward currents and the transformation of low-frequency oscillations of rat and cat thalamocortical cells. J Physiol (Lond) 441:175-197.

Spreafico R, Frassoni C, Regondi MC, Arcelli P, De Biasi S (1993) Interneurons in the mammalian thalamus, a marker of species? In: Thalamic networks for relay and modulation (Minciacchi D, Molinari M, Macchi G, Jones EG, eds), pp 17-28. New York: Pergamon.

Steriade M (1974) Interneuronal epileptic discharges related to spikeand-wave cortical seizures in behaving monkeys. Electroencephalogr Clin Neurophysiol 37:247-263.

Steriade M, Deschênes M (1984) The thalamus as a neuronal oscillator. Brain Res Rev 8:1-63.

Steriade M, Llinás RR (1988) The functional states of the thalamus and the associated neuronal interplay. Physiol Rev 68:649-672.

Steriade M, Morin D (1981) Reticular influence on primary and augmenting responses in the somatosensory cortex. Brain Res 205:67-80.

Steriade M, Timofeev I (1996) Intrathalamic mechanisms of short-term plasticity processes during incremental responses. Soc Neurosci Abstr 22:2030

Steriade M, Yossif G (1974) Spike-and-wave afterdischarges in cortical somatosensory neurons of cat. Electroencephalogr Clin Neurophysiol 37:633-648.

Steriade M, Iosif G, Apostol V (1969) Responsiveness of thalamic and cortical motor relays during arousal and various stages of sleep. J Neurophysiol 32:251-265.

Steriade M, Wyzinski P, Apostol V (1972) Corticofugal projections governing rhythmic thalamic activity. In: Corticothalamic projections and sensorimotor integration (Frigyesi TL, Rinvik E, Yahr MD, eds), pp 221-272. New York: Raven.

Steriade M, Oakson G, Diallo A (1976) Cortically elicited spike-wave afterdischarges in thalamic neurons. Electroencephalogr Clin Neurophysiol 41:641-644.

Steriade M, Deschênes M, Domich L, Mulle C (1985) Abolition of spindle oscillations in thalamic neurons disconnected from nucleus reticularis thalami. J Neurophysiol 54:1473-1497.
Steriade M, Jones EG, Llinás RR (1990) Thalamic oscillations and signaling. New York: Wiley.

Steriade M, Curró Dossi R, Nuñez A (1991a) Network modulation of a slow intrinsic oscillation of cat thalamocortical neurons implicated in sleep delta waves: cortically induced synchronization and brainstem cholinergic suppression. J Neurosci 11:3200-3217.

Steriade M, Curró Dossi R, Paré D, Oakson G (1991b) Fast oscillations $(20-40 \mathrm{~Hz})$ in thalamocortical systems and their potentiation by mesopontine cholinergic nuclei in the cat. Proc Natl Acad Sci USA 88:4396-4400.

Steriade M, McCormick DA, Sejnowski TJ (1993a) Thalamocortical oscillations in the sleeping and aroused brain. Science 262:679-685.

Steriade M, Nuñez A, Amzica F (1993b) Intracellular analysis of relations between the slow $(<1 \mathrm{~Hz})$ neocortical oscillation and other sleep rhythms of the electroencephalogram. J Neurosci 13:3266-3283.

Timofeev I, Steriade I (1996) The low-frequency rhythms in the thalamus of intact-cortex and decorticated cats. J Neurophysiol 76:4152-4168.

Timofeev I, Contreras D, Steriade M (1996) Synaptic responsiveness of cortical and thalamic neurones during various phases of slow sleep oscillation in cat. J Physiol (Lond) 494:265-278.

Uhlrich D, Huguenard JR (1996) GABA $_{\mathrm{B}}$ receptor-mediated responses in GABAergic projection neurones of rat nucleus reticularis thalami in vitro. J Physiol (Lond) 493:845-854.

Von Krosigk M, Bal T, McCormick DA (1993) Cellular mechanisms of a synchronized oscillation in the thalamus. Science 261:361-364.

Williams SR, Turner JP, Anderson CM, Crunelli V (1996) Electrophysiological and morphological properties of interneurons in the rat dorsal lateral geniculate nucleus in vitro. J Physiol (Lond) 490:129-147.

Witter MP, Groenewegen HJ, Lopes da Silva FH, Lohman AHM (1989) Functional organization of the extrinsic and intrinsic circuitry of the parahippocampal circuitry. Progr Neurobiol 33:161-253.

Yen CT, Jones EG (1983) Intracellular staining of physiologically identified neurons and axons in the somatosensory thalamus of the cat. Brain Res 280:148-154. 